\title{
New Orleans and Hurricane Katrina. III: The 17th Street Drainage Canal
}

\author{
R. B. Seed, M.ASCE'; R. G. Bea, F.ASCE'; A. Athanasopoulos-Zekkos, S.M.ASCE \\ G. P. Boutwell, F.ASCE ; J. D. Bray, F.ASCE ${ }^{5}$; C. Cheung, M.ASCE ${ }^{6}$; D. Cobos-Roa ${ }^{7}$; \\ L. F. Harder Jr., M.ASCE ${ }^{8}$; R. E. S. Moss, M.ASCE ; J. M. Pestana, M.ASCE ${ }^{10}$; M. F. Riemer, M.ASCE ${ }^{11}$; \\ J. D. Rogers, M.ASCE${ }^{12}$; R. Storesund, M.ASCE ${ }^{13}$; X. Vera-Grunauer, M.ASCE ${ }^{14}$; and \\ J. Wartman, M.ASCE${ }^{15}$
}

\begin{abstract}
The failure of the levee and floodwall section on the east bank of the 17th Street drainage canal was one of the most catastrophic breaches that occurred during Hurricane Katrina. It produced a breach that rapidly scoured a flow pathway below sea level, so that after the storm surge had largely subsided, floodwaters still continued to stream in through this breach for the next two and a half days. This particular failure contributed massively to the overall flooding of the Metropolitan Orleans East Bank protected basin. Slightly more than half of the loss of life, and a similar fraction of the overall damages, occurred in this heavily populated basin. There are a number of important geotechnical and geoforensic lessons associated with this failure. Accordingly, this paper is dedicated solely to investigating this single failure. Geological and geotechnical details, such as a thin layer of sensitive clay that was laid down by a previous hurricane, proper strength characterization of soils at and beyond the toe of the levee, and recognition of a water-filled gap on the inboard side of the sheet pile cutoff wall are judged to be among the most critical factors in understanding this failure. The lessons learned from this study are of importance for similar flood protection systems throughout other regions of the United States and the world.
\end{abstract}

CE Database subject headings: Louisiana; Hurricanes; Floods; Failures; Levees; Drainage.

\section{Introduction}

This paper is the third of a series of companion papers that, together, present the principal results of an investigation of the performance of the New Orleans regional flood protection systems during and after Hurricane Katrina, which struck the New Orleans region on August 29, 2005. This event has been the subject of numerous studies including those from the Independent Levee Investigation Team (ILIT) and the Interagency Performance Evaluation Task Force (IPET). More complete descriptions of these studies by the ILIT are available in ILIT (2006) and Seed et al. (in preparation). This paper addresses events that unfolded near the north end of the 17th Street drainage canal during and after the storm surge produced by the hurricane.

As shown in Fig. 1, the Orleans East Bank (downtown) basin is one contiguously protected section. This protected unit contains the Downtown District, French Quarter, Garden District, northern Lakeview District, and Canal District. The northern edge of this protected area is fronted by Lake Pontchartrain on the north, and the Mississippi River passes along its southern edge. The Inner
${ }^{1}$ Professor, Dept. of Civil and Environmental Engineering, Univ. of California at Berkeley, Berkeley, CA 94720-1710.

${ }^{2}$ Professor, Dept. of Civil and Environmental Engineering, Univ. of California at Berkeley, Berkeley, CA 94720-1710.

${ }^{3}$ Doctoral Candidate, Dept. of Civil and Environmental Engineering, Univ. of California at Berkeley, Berkeley, CA 94720-1710.

${ }^{4}$ Senior Consultant, Ardaman \& Associates, 316 Highlandia Dr., Baton Rouge, LA 70810.

${ }^{5}$ Professor, Dept. of Civil and Environmental Engineering, Univ. of California at Berkeley, Berkeley, CA 94720-1710.

${ }^{6}$ Engineer I, PB Americas Inc., 303 2nd St., Suite 700, San Francisco, CA 94107-1327.

${ }^{7}$ Engineer, URS Corporation, 1333 Broadway, Suite 800, Oakland, CA 94612-1924.

${ }^{8}$ Senior Water Resources Technical Advisor, HDR Inc., 2365 Iron Point Road, Suite 300, Folsom, CA 95630-8709.

${ }^{9}$ Assistant Professor, Dept. of Civil Engineering, California Polytechnic State University, San Luis Obispo, CA 93407.

${ }^{10}$ Professor, Dept. of Civil and Environmental Engineering, Univ. of
California at Berkeley, Berkeley, CA 94720-1710.

${ }^{11}$ Professor, Dept. of Civil and Environmental Engineering, Univ. of California at Berkeley, Berkeley, CA 94720-1710.

${ }^{12}$ Hasselmann Professor, Dept. of Geological Engineering, Missouri Univ. of Science and Technology, Rolla, MO 65409-0140.

${ }^{13}$ Consulting Engineer, Rune Storesund, Albany, CA 94706.

${ }^{14}$ Senior Project Engineer, CVA Consulting Group, Guayaquil, Ecuador.

${ }^{15}$ Associate Professor, Dept. of Architectural and Environment Engineering, Drexel Univ., Philadelphia, PA 19104. 


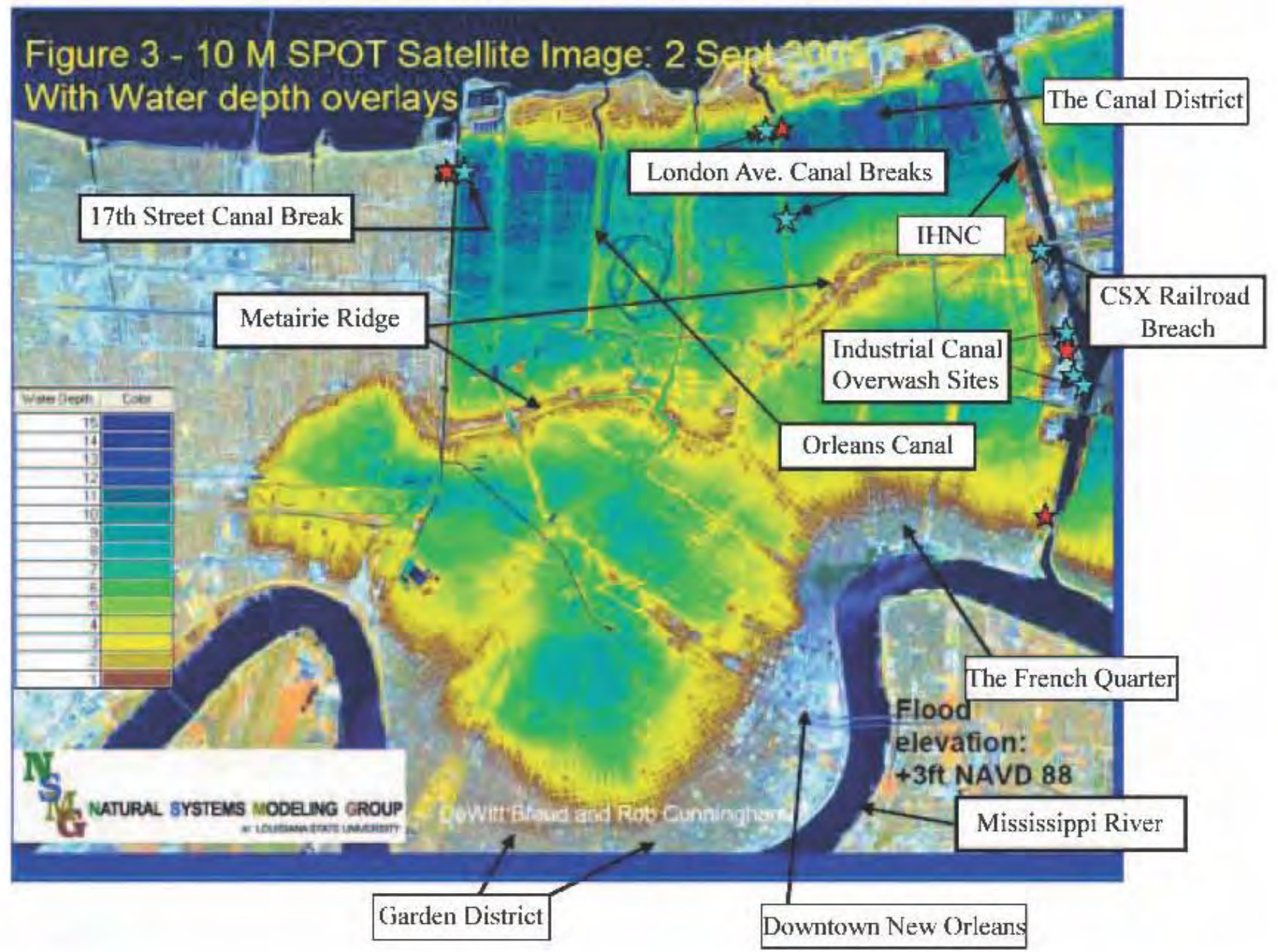

Fig. 1. (Color) Satellite view of the Metropolitan Orleans East Bank protected basin, showing depths of maximum flooding, and the locations of full levee breaches and distressed levee sections (adapted from Van Heerden et al. 2006)

Harbor Navigation Channel (IHNC) passes along the east flank of this protected section, separating the Orleans East Bank protected basin from New Orleans East (to the northeast) and from the Lower Ninth Ward and St. Bernard Parish (directly to the east). Three large drainage canals extend into the Orleans East Bank protected basin from Lake Pontchartrain to the north, for the purpose of conveying water pumped northwards from the basin into the lake by large pump stations within the city. These canals, from west to east, are the 17th Street Canal, the Orleans Canal, and the London Avenue Canal.

During the Katrina event, a majority of the flow into the Orleans East Bank basin came through the three large breaches that occurred on the drainage canals at the northern end of the Orleans East Bank protected area (ILIT 2006; Van Heerden et al. 2006; IPET 2007). As shown in Fig. 1, one catastrophic breach occurred on the 17th Street drainage canal, and two catastrophic breaches occurred on the London Avenue drainage canal. All three of these failures scoured to depths well below mean sea level, and they continued to admit flow into the city from Lake Pontchartrain well after the initial storm surge had subsided, eventually equilibrating with the still slightly swollen waters of Lake Pontchartrain on the afternoon of September 1 at a water elevation of approxi- mately $+3 \mathrm{ft}$ above mean sea level (MSL). The inflow from these three large drainage canal breaches produced a majority of the floodwaters that eventually filled more than $80 \%$ of the heavily populated Metropolitan Orleans East Bank protected basin (ILIT 2006; Van Heerden et al. 2006).

This paper presents the results of forensic investigations and analyses of the failure that occurred near the north end of the east bank of the 17th Street drainage canal. An incipient failure occurred on the opposite side (i.e., west bank) of the canal, where levee movements indicate that another failure was developing. This second incident will be discussed along with other geographically related events in the fourth companion paper of this series (Seed et al. 2008b). In this paper, the interplay between local geology, history of design, and construction, and the storm surge loading at the east bank breach site are investigated, and the observed response of the levee system is explained. Several important lessons are highlighted that will impact the repair and upgrading of regional flood protection systems in the New Orleans area, as well as in other regions in the nation and the world that also face levee-related risks. 


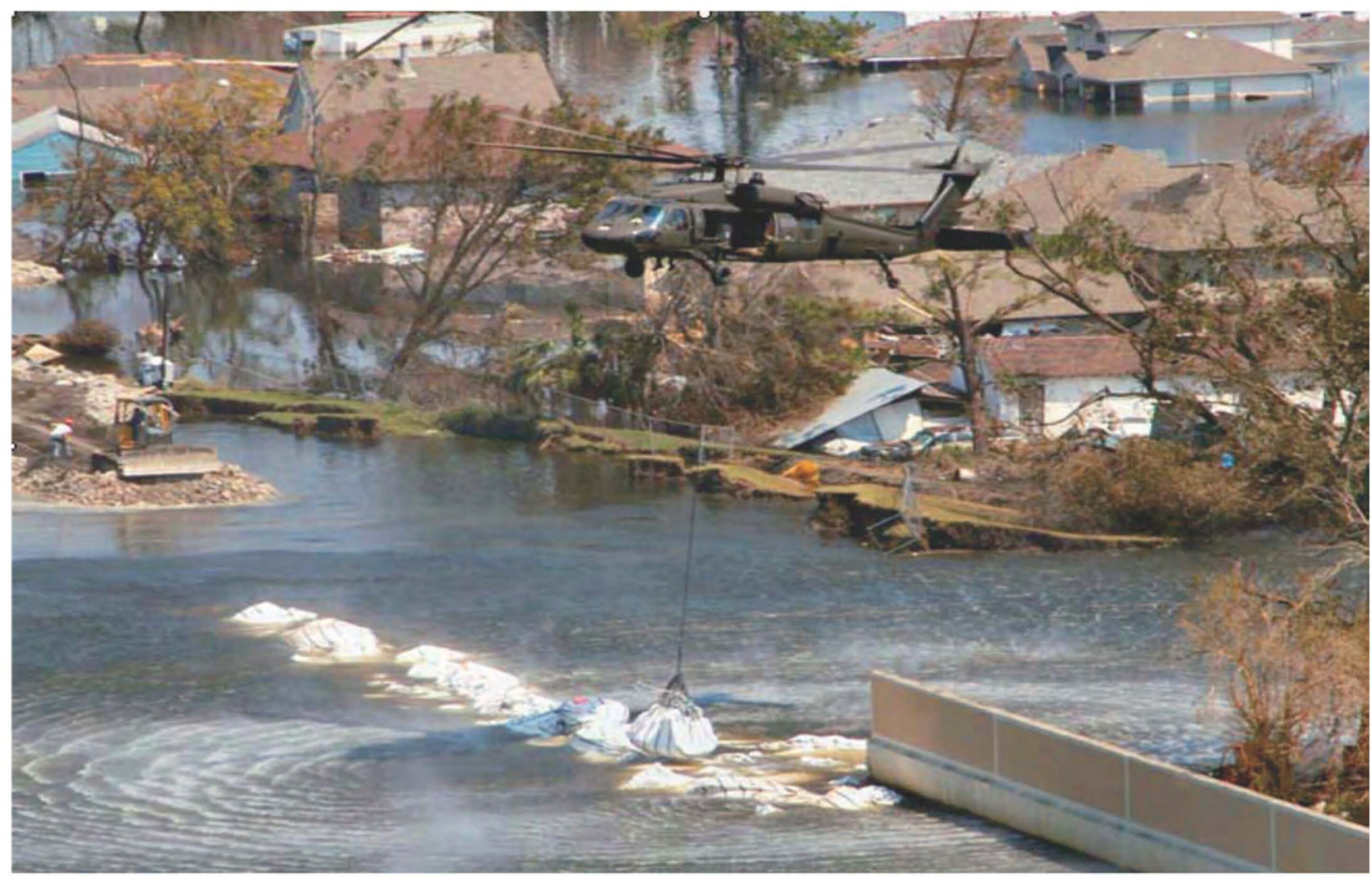

Fig. 2. (Color) Breach at the East Bank of the 17th Street Drainage Canal (USACE 1990)

\section{Failure and Breach on the East Bank}

Fig. 2 shows an oblique aerial view of the large breach that occurred on the east bank of the 17th Street canal, with a military helicopter lowering an oversized gravel-filled bag into the breach as a part of the initial closure and emergency repairs. In the photograph in Fig. 2, which was taken on September 2, 2005, it can be noted that the floodwaters have equilibrated, and the surrounding inboard-side neighborhood is fully flooded. Also shown in the middle of the photograph in Fig. 2 is the large, relatively intact section of the original embankment that has slid laterally away from the canal over a travel distance of approximately $49 \mathrm{ft}$ (with its crest fence still nearly vertical) and a small shed and a home that have been damaged near the inboard-side toe of this laterally displaced embankment section.

Fig. 3 shows a second oblique aerial view, this time looking towards the southeast. The photograph in Fig. 3 has been annotated to show the approximately $49 \mathrm{ft}$ of lateral translation of the nearly intact central section of the earthen levee embankment away from the canal. Fig. 3 also shows: (1) the still nearly level crest of the laterally displaced embankment section and the nearly vertical undamaged fence section, which indicates a lack of rotation of the overall displaced section; and (2) the top of the adjacent concrete I-wall section, which appeared to have remained in contact with the laterally displaced earthen embankment section until lateral displacements had ceased, after which it partially toppled back towards the canal as water pressures on both sides of the breach section eventually equilibrated.

To aid in the description and understanding of the mechanisms involved in this failure, generalized subsurface profiles through the breach, both before and after the failure, are shown in Fig. 4 (ILIT 2006). The displaced small shed and home shown near the center of Fig. 2 are included in Fig. 4 for visual reference. The cross sections of Fig. 4 are not schematic illustrations. Rather they are based on three-dimensional light detection and ranging (LIDAR) surveys, and visual mapping with measurements and

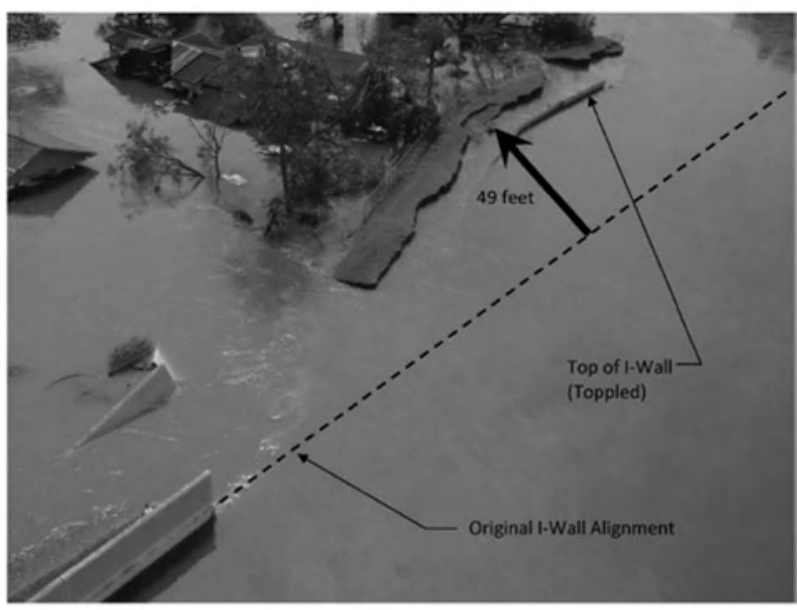

Fig. 3. Oblique aerial view of the 17th Street Canal breach on September 1, 2005, showing the lateral offset of the relatively intact central portion of the levee embankment, and the lack of rotation of the horizontal crest surface and of the intact crest fence along this displaced section (USACE 1990) 

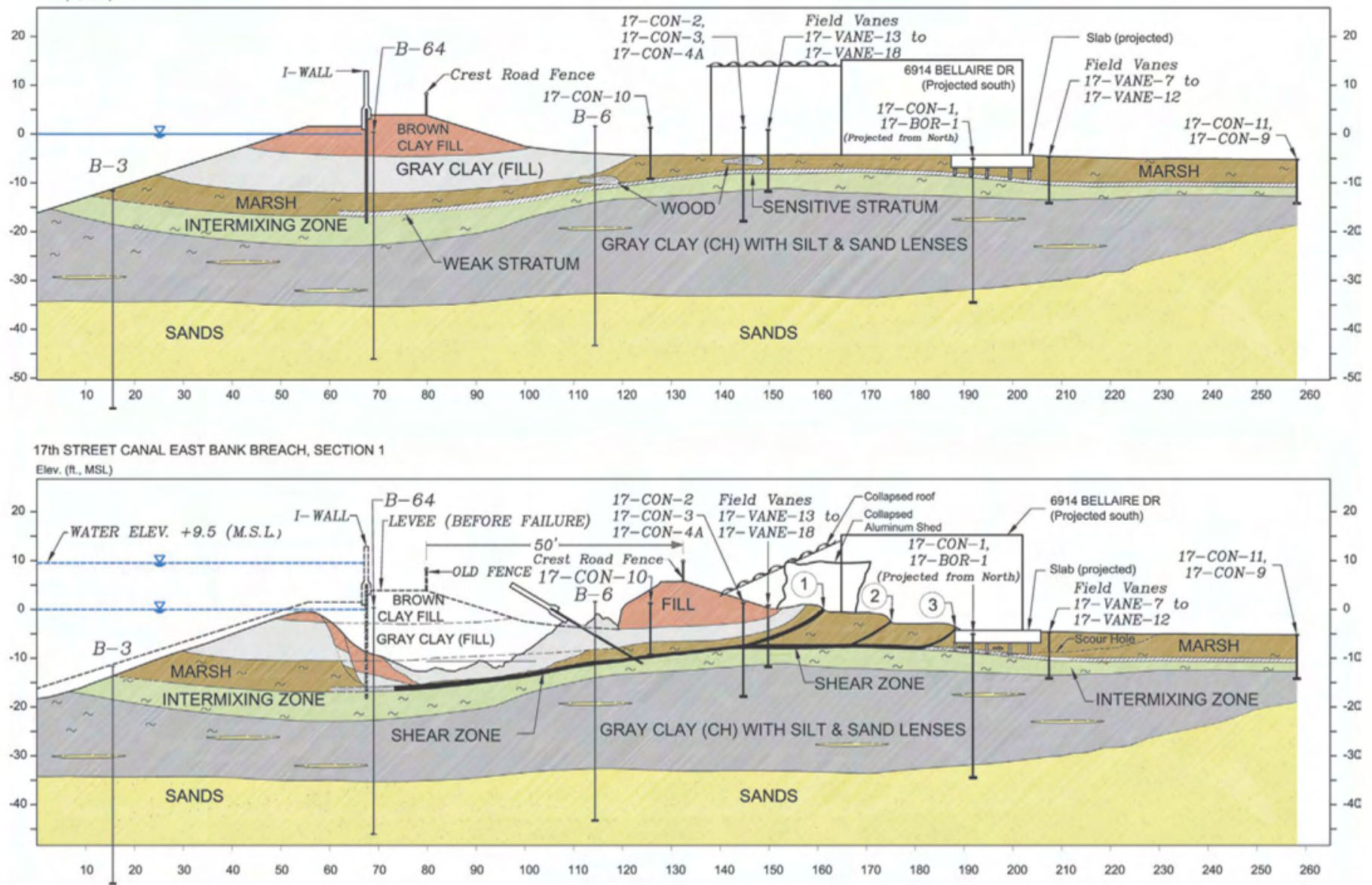

Fig. 4. (Color) Cross section through the 17th Street canal breach showing conditions before and after failure

surveys of postfailure surface details and topography. Subsurface details are based on interpretation of available boring logs, piezocone (CPTU) logs, recovered subsurface samples, and corollary laboratory test data, including both pre-Katrina data from the original design studies and post-Katrina data from both the IPET and ILIT investigation teams. The three toe scarps shown in Fig. 4 were excavated to shallow depths, and their intersections with the main shear surface were inferred based on measurements made with hand transits.

Fig. 5 shows an excavated trench through the first toe scarp at the inboard side toe of the laterally displaced levee section [Toe Scarp 1 from Fig. 4(b)]. This feature had been jointly noted and partially excavated manually by the combined ASCE and $\mathrm{Na}-$ tional Science Foundation (NSF)-sponsored ILIT field investigation teams on September 27 and 29, 2005, and was subsequently further excavated by the U.S. Army Corps of Engineers (USACE) as part of their initial IPET field investigations (IPET 2007). Fig. 6 shows the two additional toe scarps [Scarp Nos. 2 and 3 from Fig. 4(b)] that occurred further inboard (farther to the landside) from the scarp shown in Fig. 5. This breach was extensively investigated by both the IPET and ILIT investigation teams, and there are numerous additional borings and piezocone logs available at adjacent sections to the north and south of this central cross section of Fig. 4 (ILIT 2006; IPET 2007). An illustration of the sequence of evolution and progression of this failure (taken along a transect slightly north of that shown in Fig. 4), is presented in a series of six successive stages or increments in the companion paper by Rogers et al. (2008).
As depicted in Fig. 4, the inboard side of the levee embankment has been pushed laterally by the elevated waters from the canal side. During the storm, the water level within the canal rose to approximately elevation $+8 \mathrm{ft}$ above MSL, as discussed later. It is surmised that these elevated lateral water pressures eventually opened a gap at the outboard side (waterside) of the sheetpiles supporting the concrete floodwall, between the sheetpiles and the levee embankment soils; effectively cutting the earthen embankment in half. Water entered into this gap, and further increased the

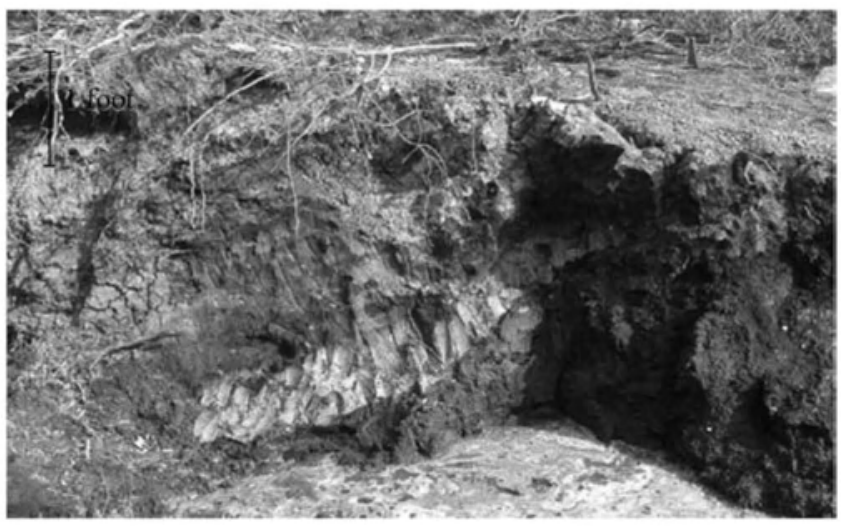

Fig. 5. View of the exit of the upper failure surface (Toe Scarp No.1), at the inboard toe of the laterally translated embankment (IPET 2006) 


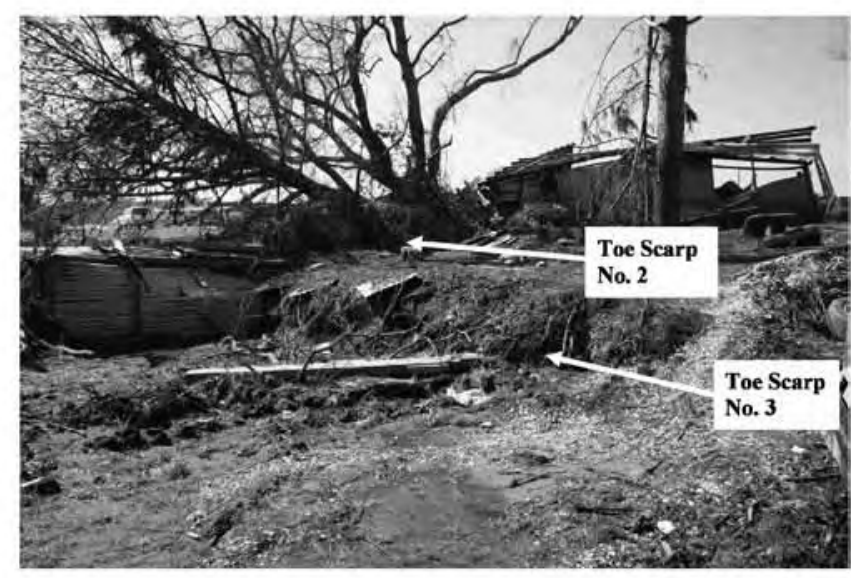

Fig. 6. View of Toe Scarp Nos. 2 and 3 at the inboard edge of the lateral translational failure at the 17 th Street drainage canal

lateral forces acting against the inboard-side half of this section, producing the eventual full lateral translational failure observed.

\section{Cross Section and Properties}

The companion paper in this volume by Rogers et al. (2008) presents a discussion of the regional and local geology relevant to this breach location. Understanding of the local geology is of paramount importance, and readers are directed there and to ILIT (2006) and IPET (2007) for more comprehensive descriptions of the geology at this site. The more concise site description that follows leans heavily on this understanding of the overall geological context, and also on (1) the available pre-Katrina site data; and (2) the extensive post-Katrina site investigations and laboratory testing programs performed by both the ILIT and IPET investigation teams (ILIT 2006; IPET 2006, 2007).

As shown in Fig. 4, the top of the concrete floodwall was at approximately elevation $+12.4 \mathrm{ft}$ above MSL, and the crest of the earthen levee embankment section was at elevation+6 ft (MSL). The elevation of the land on the protected side of the levee toe was at approximately elevation $-4.5 \mathrm{ft}$ (MSL). The levee embankment consisted of two separate sections. The upper, modern, semicompacted embankment consisted mainly of brown clay and silty clay of medium-to-high plasticity ( $\mathrm{CH}$ and $\mathrm{CL})$. This was underlain by older embankment sections, comprised largely of locally available gray freshwater marsh and cypress swamp deposits, herein referred to as marsh deposits, and lacustrine clays $(\mathrm{CH})$ placed without modern compaction over the preceding century.

The levee embankment was underlain by marsh deposits varying from a few feet to as much as $8 \mathrm{ft}$ in thickness, and these were underlain by a transition zone of interbedded marsh and lacustrine/paludal (i.e., freshwater) clay deposits of similar thickness. These marsh deposits were organic-rich, peaty soils, variably mixed with clayey mineral sediments. These, in turn, were underlain by a layer of soft, gray high-plasticity lacustrine clay $(\mathrm{CH})$. These soft gray clays were underlain by fine sands. These sands are sufficiently strong and competent relative to the weaker overlying marsh and clay units that they were not involved in the failure. Similarly, although these sands were relatively pervious, this was not a significant issue at this site as they occurred at sufficient depth that they were effectively capped with regard to

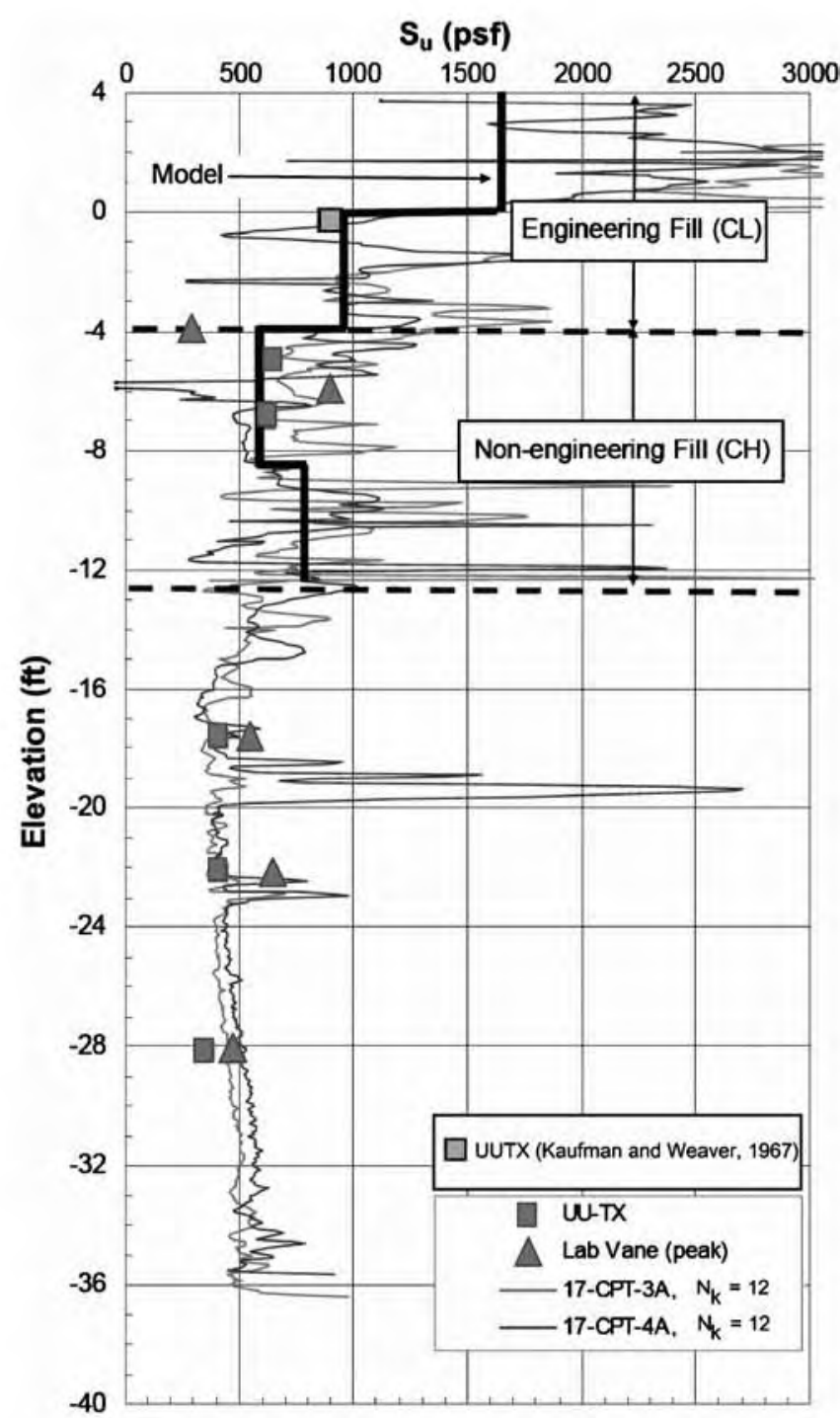

Fig. 7. Summary of shear strength data within the 17th Street drainage canal levee embankment fill at and near the east bank breach section

underseepage potential by the relatively thick and low permeability layer of soft gray clays.

Fig. 7 shows the shear strength data for the levee embankment soils at the breach site. Both the upper (engineered fill) and lower (nonengineered fill) embankment zones had significantly higher shear strengths and stiffnesses than the underlying foundation soils, so the shear strengths of these embankment soils were not a critical issue in this failure. The embankment section was split by the I-wall and its supporting sheetpile curtain, and traveled largely as a monolithic block during the failure. The heavy solid black lines in Fig. 7 show the shear strengths modeled for the upper and lower embankment fill zones in the analyses.

The shear strengths of the foundation soils underlying the levee embankment were critical issues. Accordingly, investigation of the strengths and stiffnesses of (1) the upper marsh stratum; (2) the intermediate transitional stratum; and (3) the lower soft, gray paludal clay stratum are of great importance. Detailed characterization of these soils, including full derivations of soil strengths and stiffnesses, are provided by ILIT (2006), and they are outside the scope of this paper. Abbreviated descriptions are provided below. 

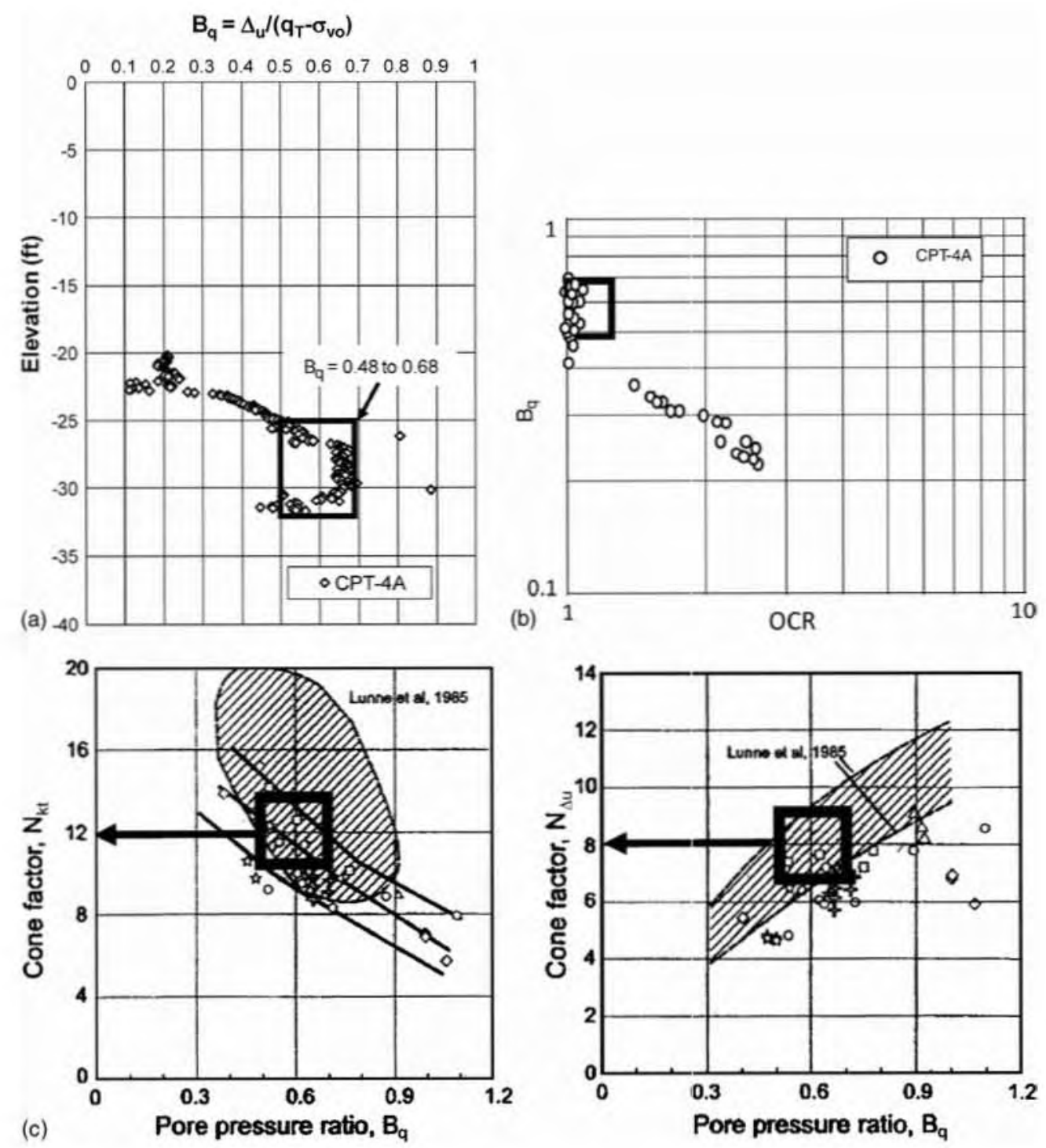

Fig. 8. (a) Pore pressure ratio coefficient $B_{q}$ versus OCR and $B_{q}$ versus depth within the soft gray clay $(\mathrm{CH})$ foundation layer under the full height embankment overburden load; (b) CPT cone factor $N_{k t}$ based on $B_{q}$ [adapted from Lunne et al. (1985) and Karlsrud et al. (1996)] for the soft gray clay $(\mathrm{CH})$ under full embankment overburden load

\section{Soft Gray Clays}

The principal sources of data regarding characterization of the soft gray clay stratum were: (1) relatively "undisturbed" samples obtained with thin-walled fixed-piston samplers and then subjected to laboratory testing; (2) piezocone penetration test probes (CPTU); and (3) a limited number of in situ vane shear strength tests.

High-quality 2.8-in.-diameter fixed-piston samples of this soft clay stratum were obtained by eliminating the inward "roll" of the thin-walled sampling tubes, thus minimizing lateral expansion of the samples as they entered into the sampling tube by reducing the inside clearance ratio ( $\mathrm{ICR} \sim 0)$. This technique has been recommended as one of the practical solutions for reducing sample disturbance effects in these types of soft clays (e.g., Ladd and DeGroot 2003; DeGroot et al. 2005). Unconsolidated-undrained triaxial tests (UUTX) tests were then performed on smaller diameter specimens hand carved from these samples. The initial (preKatrina) design field investigations had used mainly UUTX tests performed on specimens trimmed from 5-in.-diameter thin-walled fixed-piston samples, and the postfailure IPET investigation also made significant use of these same methods.

Because neither of the above techniques (relatively large diameter samples or improved sampler cutting edges) fully eliminates sampling disturbance effects, it was judged that the most reliable strength interpretation for these soft soils was obtained by careful processing of the in situ data from the CPTU probes. The ILIT and IPET investigation teams developed CPT-based estimates of the undrained shear strengths of these lower clays based on the standard equation $s_{u}=\left(q_{c}-\sigma_{v o}\right) / N_{k t}$, where $s_{u}=$ undrained shear strength; $q_{c}\left(\right.$ or $\left.q_{t}\right)=\mathrm{CPT}$ tip resistance; $\sigma_{v o}=$ initial total vertical stress; and $N_{k t}=$ cone tip coefficient. Using the full suite of piezocone data, including pore pressure measurements, and the relationships of Lunne et al. (1985) as extended by Karlsrud et al. (1996), the material-specific CPT tip coefficient was found to be $N_{k t}=12$, based on the pore pressure ratio coefficient of $B_{q}=\Delta u /\left(q_{c}-\sigma_{v o}\right)=0.48-0.68$ (where $\Delta u=$ excess porewater pres- 


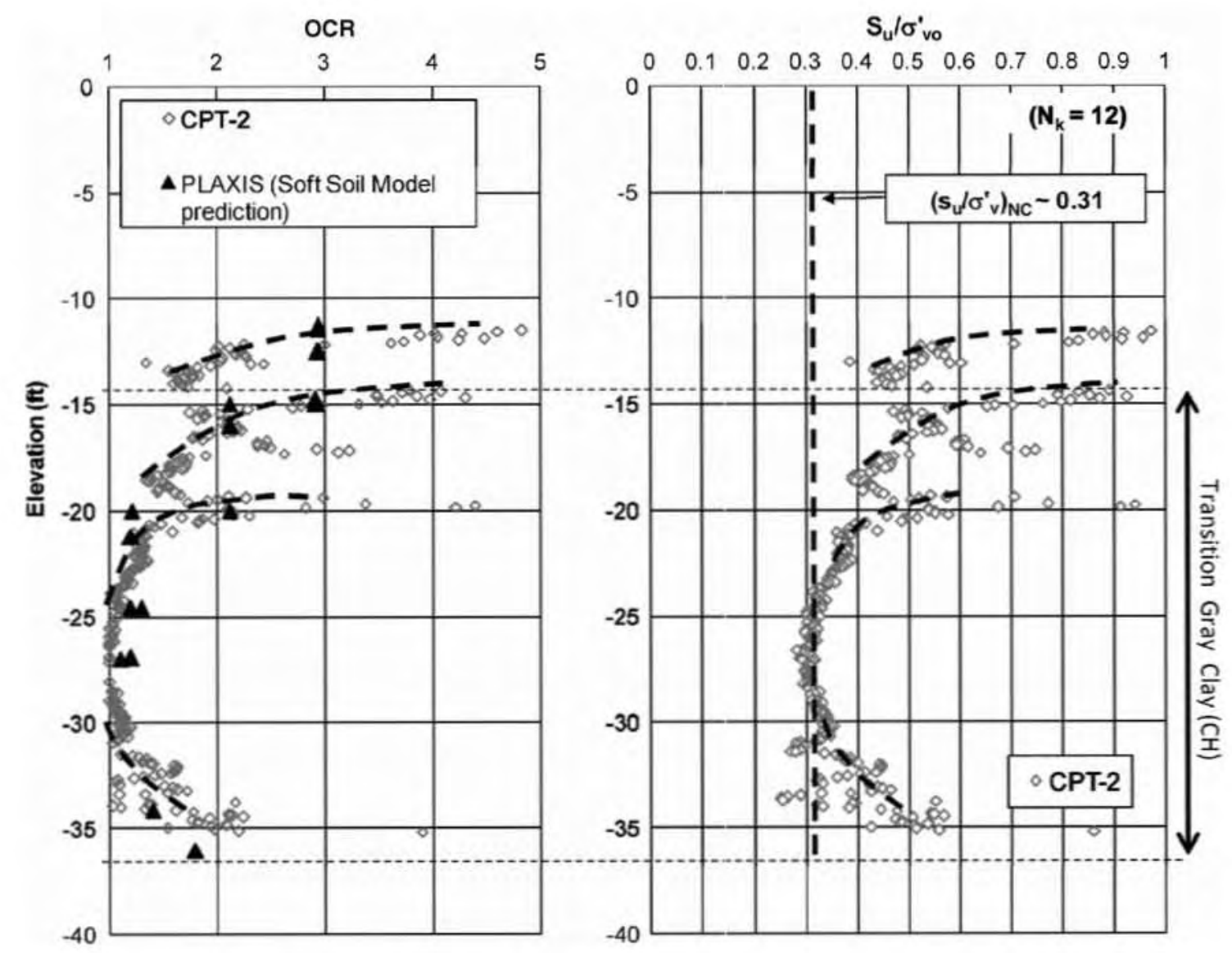

Fig. 9. Plots of (a) OCR versus depth; (b) $S_{u}$ versus depth for the soft gray marsh clay $(\mathrm{CH})$ at the inboard toe and further to the landside (not under levee embankment overburden pressure)—17th Street Canal breach site

sure) for the normally consolidated portion of this soft clay unit, as shown in Fig. 8 (see ILIT 2006 for more details). The selected tip coefficient of $N_{k t}=12$ differed from the non-site-specific value of $N_{k t}=15$ assumed by others (e.g., IPET 2007), and resulted in a slightly different interpretation of strengths for this lower, soft gray clay stratum. For example, the IPET strengths were about 15-20\% lower than the ILIT strengths within the normally consolidated portions of the profile, and were lower by even larger amounts in those parts of the profile that our (ILIT) investigation judged to be overconsolidated.

Based on a characterization procedure suggested by Pestana (ILIT 2006), the shear strengths estimated based on the materialspecific CPTU tip coefficient $\left(N_{k t}\right)$ could be interpreted through an inverse stress history and normalized soil engineering parameters (SHANSEP)-type regression to simultaneously evaluate: (1) the apparent overconsolidation profile versus depth; and (2) the corresponding values of undrained shear strength versus effective overburden stress $\left(s_{u} / \sigma_{v o}^{\prime}\right)$ as a function of the overconsolidation ratio (OCR), for both normally consolidated and overconsolidated portions of the soil stratum. Fig. 9 shows the resulting profiles of OCR and normalized shear strength $s_{u} / \sigma_{v o}^{\prime}$ versus depth for the soft gray foundation clay and also for the upper marsh strata at a location directly below the inboard (landside) toe of the levee embankment. In Fig. 9, the lower two overconsolidated zones are within the lower soft clay stratum, and the upper overconsolidated zone is within the intermixed clays and marsh deposits. As shown in Fig. 9, the foundation soils are interpreted to not be normally consolidated; instead, they exhibit at least three distinct overconsolidation crusts likely due to periodic exposure and desiccation during at least three separate periods during the progressive accretion of these deposits during the Holocene. In addition, the base of the deeper clay stratum appears to be slightly overconsolidated, which may be attributed to the rapid initial consolidation near to the pervious drainage layer as well as secondary compression effects (Rogers et al. 2008). In contrast, the IPET investigation considered this layer to be normally consolidated over its full depth (IPET 2006, 2007).

The three overconsolidated crusts were found to be less pronounced beneath the central portion of the levee embankment, as the higher overburden stresses introduced by the construction of the overlying levee embankment, reduced the OCR in that region to those of nearly normally consolidated soil conditions. However, the strengths of the soils under the center of the embankment are significantly less important than those of the soils beneath and adjacent to the inboard-side toe of the levee for evaluating the potential for lateral or rotational embankment instabilities. The available data clearly suggest three distinct and significant desiccation-type overconsolidation crusts existed in the foundation soils beneath the inboard toe of the 17th Street drainage canal levee at this site.

The overall regression of the CPTU data resulted in a best-fit value of $\left(s_{u} / \sigma^{\prime}\right)_{N C, T X}=0.31$ for the normally consolidated soft gray paludal clay zones, and a SHANSEP coefficient of $m=0.75$ defining the relationship between $s_{u} / \sigma_{v}^{\prime}$ and OCR [i.e., $s_{u} / \sigma_{v}^{\prime}$ $\left.=\left(s_{u} / \sigma_{v}^{\prime}\right)_{N C} \times \mathrm{OCR}^{m}\right]$ (Ladd and Foott 1974). These are fairly typical values for clays of this plasticity, and they are in excellent agreement with the values determined by Foott and Ladd (1977) for the well-studied clays at the nearby Atchafalaya River basin 


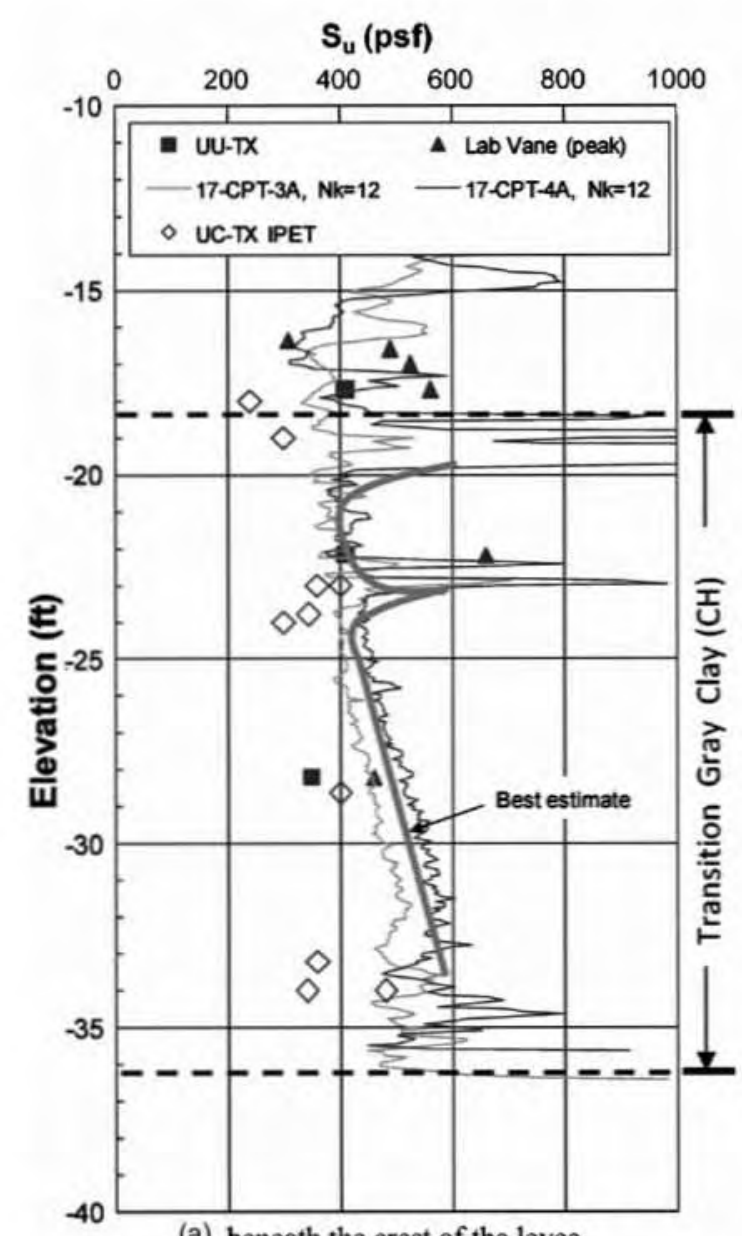

(a) beneath the crest of the levee

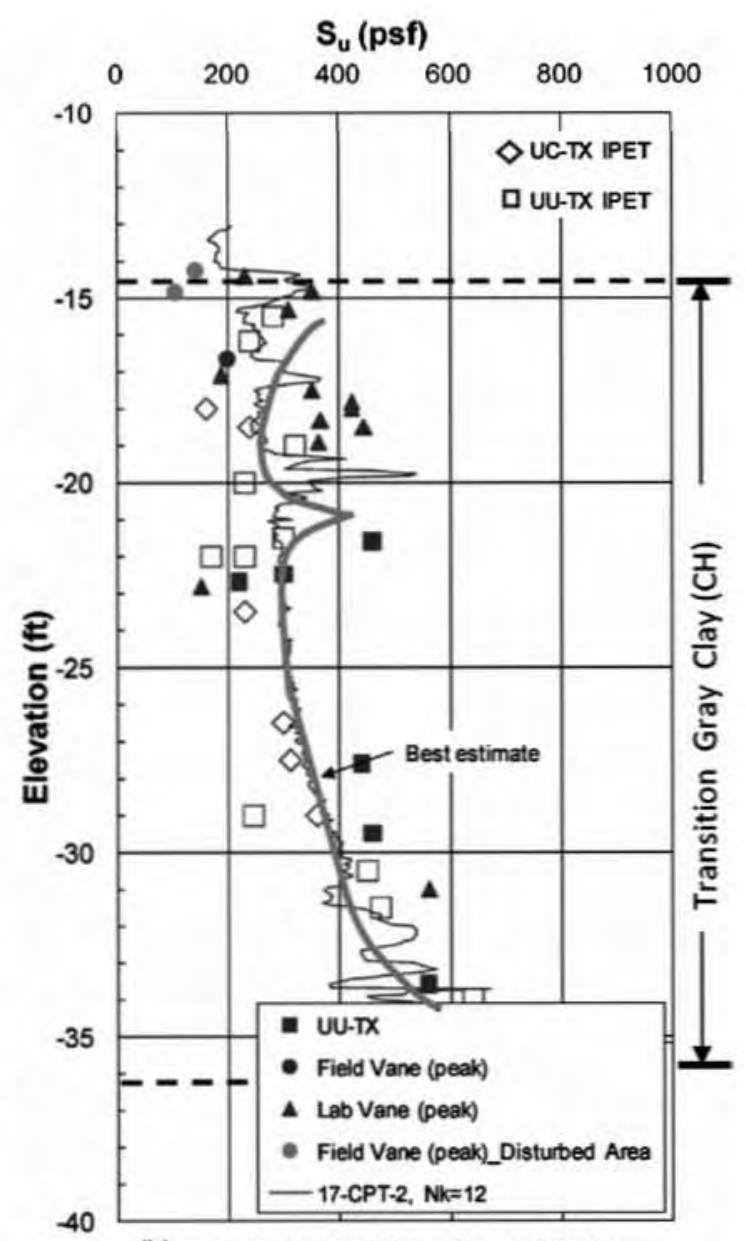

(b) at and near the inboard toe of the levee

Fig. 10. Profiles of shear strength versus depth within the soft gray foundation clay at the 17th Street Canal breach site: (a) beneath the crest of the levee; (b) at and near the inboard toe of the levee, including the ILIT, IPET, and pre-Katrina data

and with the values of clays of similar plasticity from a larger database (e.g., Ladd and DeGroot 2003). The Atchafalaya clays have similar mineralogy and derive their source materials from the same Mississippi River drainage system.

The solid lines in Fig. 10 show the resulting profiles of undrained shear strength within the soft gray clay foundation stratum (a) beneath the crest of the levee, and (b) beneath the inboard side levee toe, based on $\left(s_{u} / \sigma_{v}^{\prime}\right)_{N C}=0.31$ and $m=0.75$ for triaxial compression conditions. The two overconsolidated horizons within these clays are apparent in Fig. 10. The results of UUTX tests on "relatively undisturbed" ILIT samples, laboratory vane shear tests (LVST) on ILIT samples, and in situ field vane shear strength tests (FVST) are shown in Fig. 10 for completeness. Agreement between the interpretation derived based on the inverse regression of the CPTU data with the other data is good, and the overall fit of the modeled strength profiles to all of the data is reasonable.

The shear strength profiles of Fig. 10 were next modified further to account for the direct simple shear (DSS) mechanism that would dominate the primary deformation response in the field for the types of stability failure mechanisms under consideration. The strengths shown in Fig. 10 are appropriate for triaxial compression stress paths $\left(s_{u, T X}\right)$, and so they need to be modified to produce values appropriate for analyses of stress paths better represented by DSS conditions $\left(s_{u, \mathrm{DSS}}\right)$. A reduction of undrained shear strength, by multiplication by a factor of 0.82 , was applied as $s_{u, \mathrm{DSS}}=0.82 \times s_{u, T X}$. The factor of 0.82 accounts jointly for both stress path and material strength anisotropy according to the work of Ladd and DeGroot (2003) and observed by other researchers (e.g., Pestana et al. 2002), as shown in Fig. 11. This adjustment is similar to the DSS strength reduction factor previously found to be applicable to the mineralogically similar Atchafalaya River basin shallow lacustrine clays (Foott and Ladd 1977).

For conventional limit equilibrium analyses, the resulting strengths were then reduced by an additional $10 \%$ to account for sensitivity (the ratio of peak undrained shear strength versus residual strength) and resultant progressive rupture, based on the work of Chirapuntu and Duncan (1975). In summary, the undrained shear strengths of this gray clay were thus modeled based on OCR values that varied spatially across the domain, $\left(s_{u} / \sigma_{v}^{\prime}\right)_{N C \text {,DSS }}=0.23$, for the normally consolidated zones, and a SHANSEP coefficient of $m=0.75$ defining the relationship between $s_{u} / \sigma_{v}^{\prime}$ and OCR for other regions in the domain.

Finite-element analyses were performed using the commercially available code PLAXIS (Brinkgreve 2007). In these analyses, the soft soil model, an isotropic effective stress constitutive model, was used to simulate the foundation clay stratum. One significant shortcoming of this model is the inability to simultaneously match the friction angle in drained tests and the undrained shear strength in undrained tests, unlike other more sophisticated clay models (e.g., Pestana et al. 2002). Despite this and other shortcomings, the model captures the effects of stress 


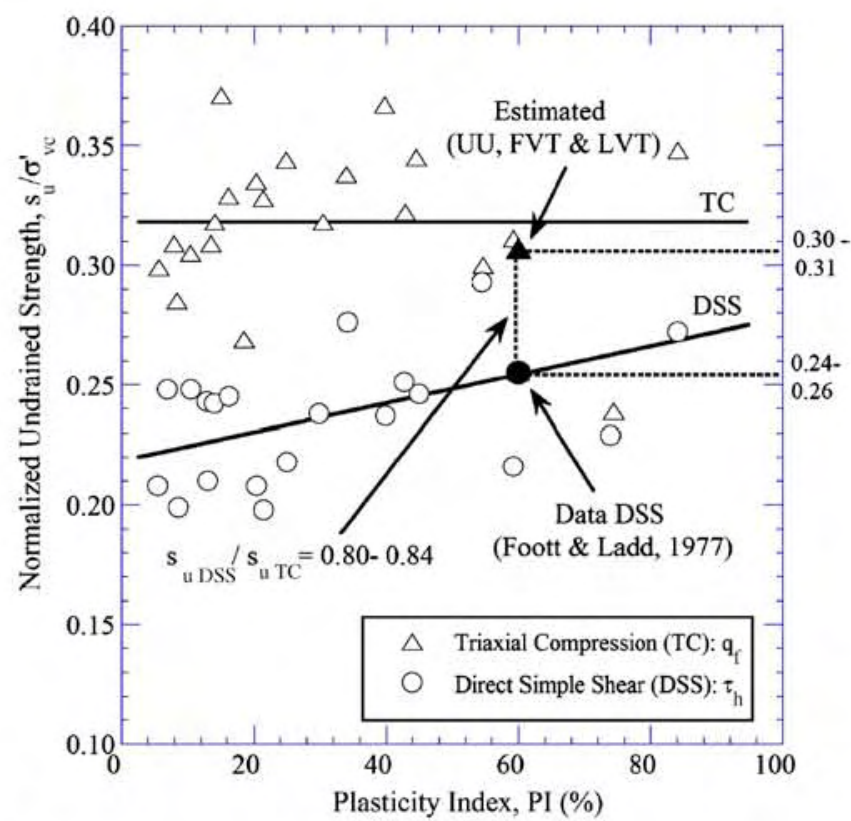

Fig. 11. Undrained shear strength for UU-triaxial loading versus undrained shear strength for DSS loading (adapted from Ladd and DeGroot 2003)

history and it is possible to calibrate the model parameters to match the undrained strength profile as well as the compression characteristics (with two different sets of properties).

The numerical analyses presented here assumed essentially undrained shearing conditions during the rapidly rising hurricane storm surge loading. Development of parameters for the soft soil model was an iterative process, and concentrated on achieving the targeted undrained shear strength (as a function of effective vertical stress and overconsolidation ratio at each point) for DSS modes in single element tests, as described previously. The effective friction angle $\left(\phi^{\prime}\right)$ and the additional model parameters defining compressibility properties $\left(\lambda, \kappa\right.$, related to $C_{c}$ and $\left.C_{r}\right)$ were calibrated so that the overall model response corresponded to undrained shear strengths (in DSS mode) representing $\left(s_{u} / \sigma_{v}^{\prime}\right)_{N C \text { DSS }}=0.23$ for the normally consolidated clay, and a SHANSEP coefficient of $m=0.75$. Numerical simulations using an updated Lagrangian approximation to simulate the large settlements resulting from the placement of the embankment were used to calibrate the compressibility parameters and obtain the approximate current (pre-Katrina) configuration. Similar calibration exercises have been conducted successfully to match observed pore pressure response, lateral deformations, and settlements of other levees during construction (e.g., URS/ARUP 2005). A suite of single elements were modeled at various lateral and vertical locations within the soft gray foundation clays to confirm the achievement of this targeted response. The effective friction angle of $\phi^{\prime}=36^{\circ}$ shown in Table 1 does not represent a drained friction angle, but it is instead chosen to match the undrained strength as described previously, given the intrinsic limitations of the soft soil model. Analogous modeling for triaxial space conditions was also performed and results from such "element-level" tests, at locations directly beneath the inboard toe of the embankment, are shown by the large black triangles in Fig. 9; the match is excellent. No parameters were developed to model the "drained" response after the failure event. A more complete description of the calibration process is found in ILIT (2006).

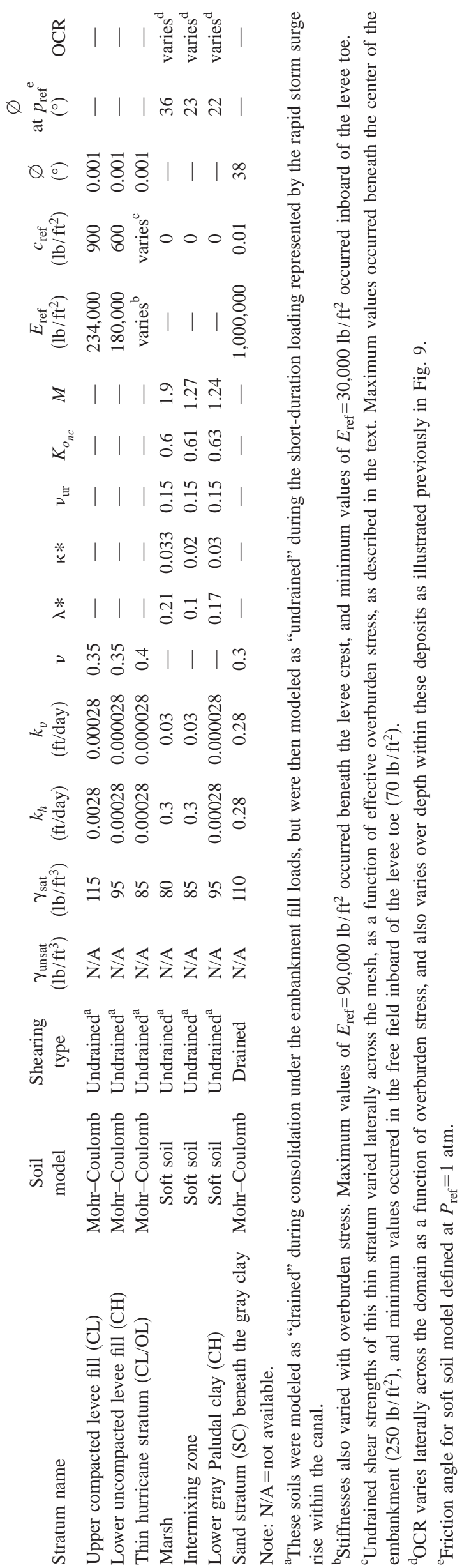



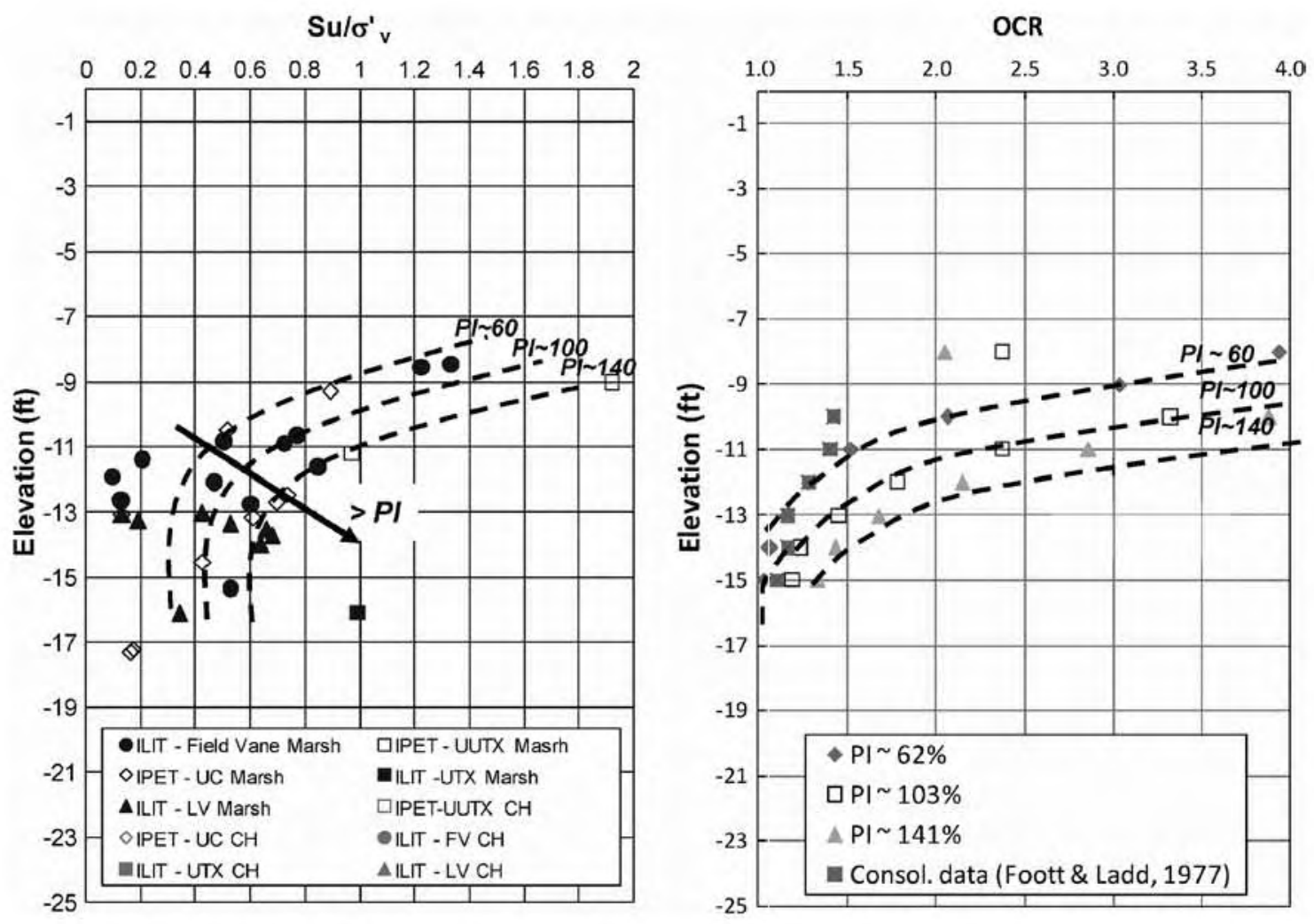

Fig. 12. Undrained shear strength versus depth, and OCR versus depth, within the marsh deposits beneath the inboard toe based on Mayne and Mitchell (1988) - 17th Street Canal breach site

\section{Upper Marsh Deposits and Transitional Zone}

The upper marsh deposits, and the upper transitional deposits representing variably mixed marsh and clay strata, were somewhat more difficult to characterize. Similar application of the CPTUbased relationships of Lunne et al. (1985) and Karlsrud et al. (1996) resulted in establishment of a material-specific CPT tip coefficient $N_{k t} \approx 16$ for these units. This was close to the nonmaterial-specific value of $N_{k t} \approx 15$ used by the IPET investigation for these marsh and clay foundation strata (IPET 2007). Fig. 9 shows the interpretation of shear strengths within these upper marsh and transitional strata based only on the CPTU data (using $N_{k t} \approx 15$ for the marsh and $N_{k t}=12$ for the underlying clay deposit). Our (ILIT) values of shear strength in these potentially important upper marsh and transitional clay strata were next cross checked using an empirical relationship between undrained shear strengths and water content $\left(w_{o}, \%\right)$ and plasticity index (PI, \%) developed by Mayne and Mitchell (1988) for these types of soils. Fig. 12 shows this second interpretation; a comparison between the various other types of shear strength data available within the upper marsh stratum [UUTX, consolidated-undrained triaxial text (CUTX), and FVST] based on the relationship proposed by Mayne and Mitchell (1988). There was good agreement between these two methods of strength interpretation for these marsh and transitional strata.

Fig. 13 then shows the interpreted resulting overall shear strengths as modeled within the marsh and upper transition zone at two locations: (a) beneath the crest of the levee; and (b) at the inboard-side levee toe. The heavy, solid lines indicate the representative undrained shear strengths as modeled in the numerical analyses. The shear strengths within these marsh deposits were, in general, slightly higher than the undrained shear strengths of the underlying soft, gray clays. A single, localized exception was the "sensitive zone" that occurred near to the base of the marsh deposits, as shown in Fig. 13, and this will be discussed in the section that follows. Compatible soil parameters were then developed for the soft soil model to capture the targeted undrained shear strength values for these upper marsh and transition strata (ILIT 2006), as was described for the underlying soft gray clays in the preceding section.

\section{Critical Soil Stratum}

The zone indicated in Fig. 13 as the sensitive zone was a semicontinuous stratigraphic horizon in the vicinity of the breach area, which contained a thin layer of sensitive organic clay. As noted previously in Fig. 4, this layer was only approximately $0.8-1.2$ in. $(2-3 \mathrm{~cm})$ in thickness, and was found to extend fully across the breach area, along the east side of the canal. The depth at which this thin stratum occurred varied slightly across the site, so the zone within which this critical stratum occurred appears to be thicker in Fig. 13 than the actual stratum thickness of approximately $1 \mathrm{in}$. It was easily missed in many of the borings advanced by the ILIT team, requiring three rounds of sampling for each successful sample, due to its high water content and sensitivity (Rogers et al. 2008).

Fig. 14(a) shows a photograph of the sensitive layer, believed to have served as the basal rupture surface beneath the translated blocks shown previously in Fig. 3 and depicted in Fig. 4. The sample shown in Fig. 14(a) was obtained from within the shear failure zone, and has been remoulded to a residual condition. The layer exhibited physical evidence of having been unidirectionally sheared and remolded in situ, and in the direction of the observed 

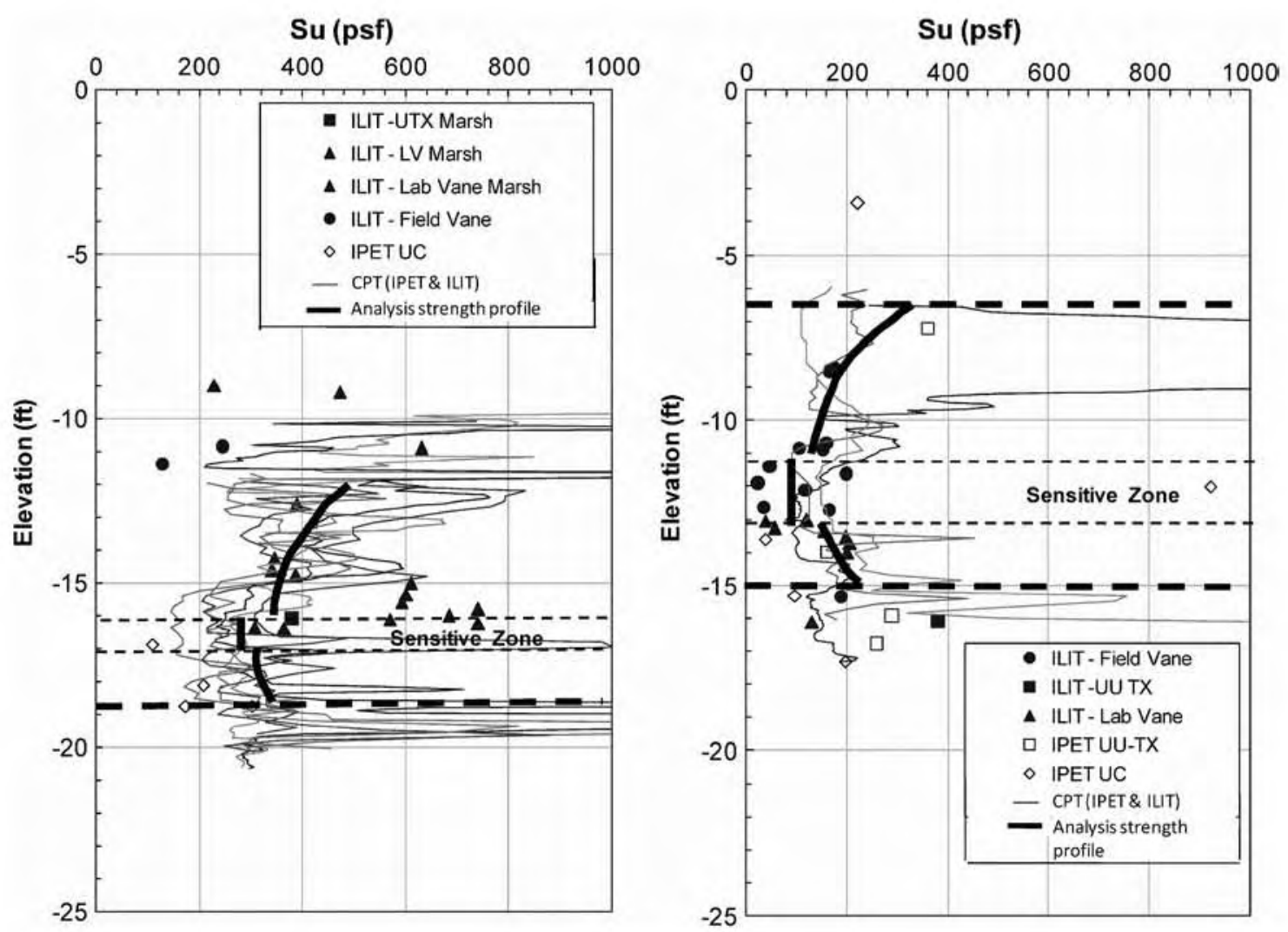

Fig. 13. Shear strength versus depth within the marsh deposits at the 17th Street Canal breach site: (a) beneath the crest of the levee; (b) at the inboard toe

translational failure, as demonstrated by the unidirectional pulling and tearing of organic fibers (up to $5 \mathrm{~cm}$ thick), and it exhibited an unusually low (nearly zero) residual strength (ILIT 2006). This is the stratum along which the main translational shear failure is hypothesized to have occurred at this site. Fig. 14(b) shows another sample of the sensitive layer; this time recovered from an area well outside of the August 2005 failure zone, and so representing a more nearly undisturbed specimen. These relatively undisturbed samples exhibited distinctive contrasts from those in the failure zone insofar that they appeared much less disturbed and without snapped branches, dragged organics, or water-filled large voids. The sensitive layer also contained discernible sequences of organic, peaty materials, and soft clays. The nearby soft clays do not exhibit a glossy character, and at in situ water contents they appear flat and dull. The layer of sensitive organic silty clay is starkly different. As shown in Fig. 14(b), this material is highly glossy, and is also somewhat translucent. This material is softer than the nearby soft clays and marsh deposits, and it is exhibited greater sensitivity during shear testing.

It was difficult to locate this thin layer initially with conventional site investigation methods. This layer had been deposited as a result of a previous hurricane, approximately 600-700 years ago based on carbon dating of pollens from a sample of this material (ILIT 2006). That hurricane had temporarily changed the local depositional regime, churned up organics and silts, and mixed them with the locally available suspended clays, and laid down a thin layer that was flocculated due to the increased salinity caused by the storm. The brackish seawater served as an effective flocculant, triggering a faster deposition of the suspended fines, followed by dead organics, killed by the brackish water intrusion. The hurricane winds, and the salt, also produced wind-blown or- ganic detritus and a vegetation die off, so that a layer of leaves and occasional twigs varying from about 4 to $10 \mathrm{in}$. in thickness was then deposited immediately above this very weak, sensitive thin clay layer. When drilling down, these leaves and twigs obstruct sampling. When the hole is suitably cleaned out for sampling; the very thin layer may also have been removed. Similarly, when pushing a CPT through the obstructing overlying organic detritus, by the time the tip and sleeve readings begin to clear this layer of detritus material to sense the thin layer, the thin stratum has often been largely passed through. Fig. 14(c) shows the shiny material of this thin stratum coating the outside of the soils adhered to the base of the auger flight. When these soils are then peeled open [the inset in Fig. 14(c)], the organic (fibrous and twiggy) character of the obscuring overlying organic detritus is revealed.

During the original (pre-Katrina) site investigations for initial design, multiple adjacent borings at the site failed to retrieve samples at this same depth (ILIT 2006; Rogers et al. 2008). This failure to retrieve samples at the same depth in adjacent boreholes might have served as an indication that something unusual was present. The post-Katrina borings performed as part of the IPET investigation also failed to retrieve samples of the critical thin sensitive clay stratum, but this thin layer can in hindsight be seen in a number of the post-Katrina electronic CPTU logs performed as part of that investigation (IPET 2007).

The ILIT effort initially experienced similar difficulties in its attempt to retrieve samples of this thin stratum. The overlying fibrous material made it difficult to access, and the material itself was so weak and sensitive that it would not sustain the tension necessary to retain samples within the sampling tubes. A modified approach was developed which involved drilling down until the 


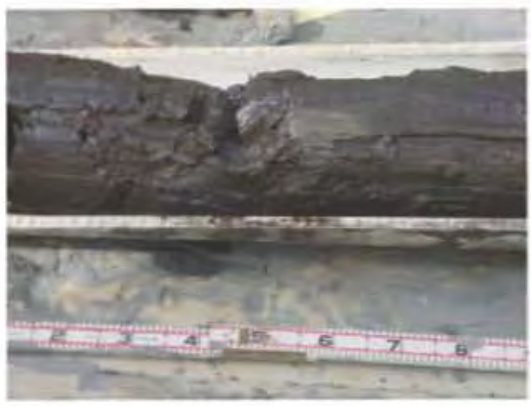

A

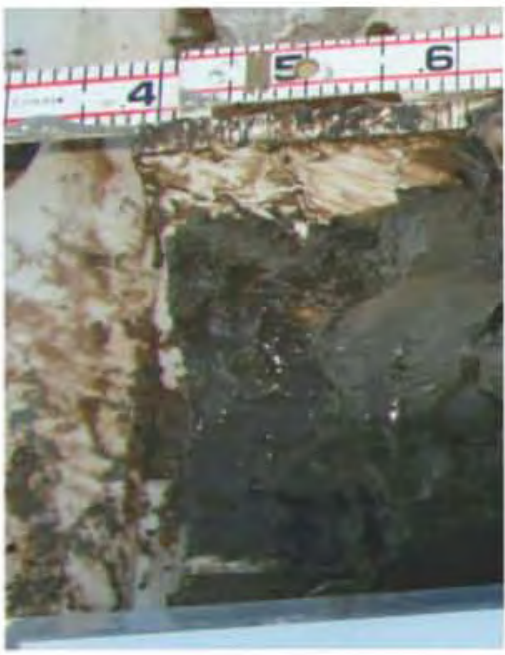

B

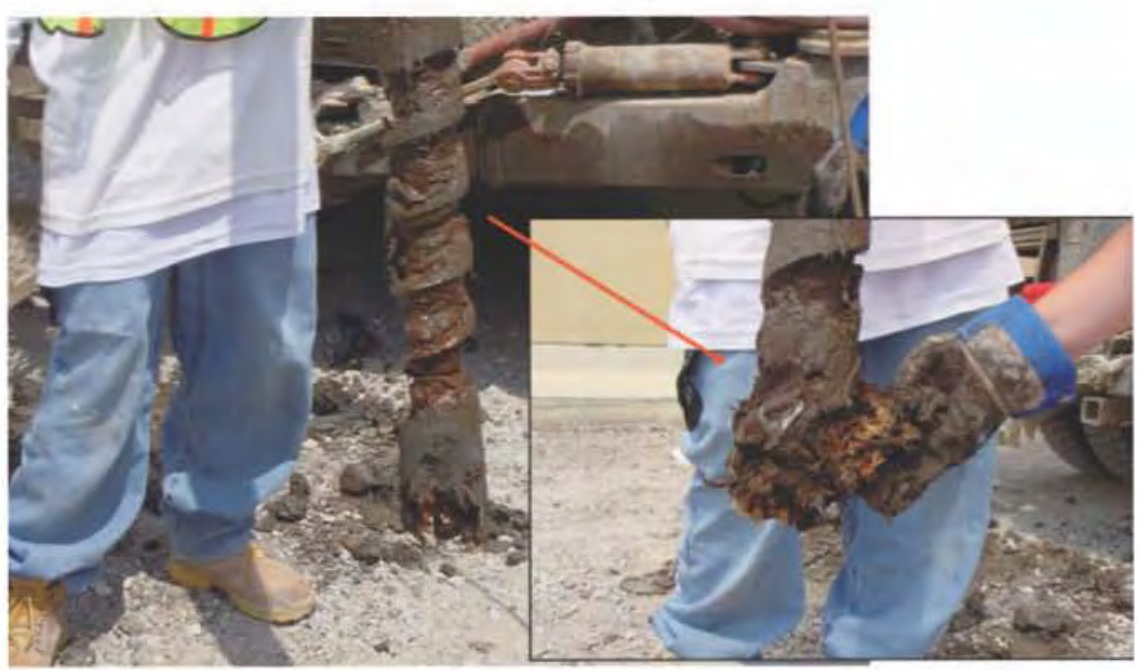

C

Fig. 14. ( Color) (a) Sheared sample of the sensitive organic silty clay layer from within the slide area; (b) unsheared sample of the same material from near to the slide area, but not within it; and (c) shiny dark brown to black sensitive organic clay on auger stem and (inset) closeup view of layers of leaves and twigs-17th Street Canal breach site

closely overlying organic detritus layer was encountered and then drilling slowly through this layer to identify its base. Then, a second hole was drilled adjacent to the previous hole until the depth of the base of the organic detritus had nearly been reached (usually within approximately $4 \mathrm{in}$. of the top of the targeted thin underlying organic silty clay stratum). A thin-walled (very sharpedged) sampling tube was then pushed well below the base of the thin stratum (oversampling past the thin stratum by at least $2 \mathrm{ft}$ ), so that the firmer soils underlying this stratum would plug the base of the sampler allowing the soft horizon to be successfully retrieved.

Once samples of this material had been obtained, the next problem was to ascertain its shear strength characteristics. That was accomplished in the laboratory by using a pipe cutter to trim the tubes down slowly in 2-in. increments, using stiffeners to maintain the circularity of the tube during cutting (to avoid disturbance), and then carefully excavating the material within the tube by hand. When the organic detritus had been cleared, and the thin, sensitive layer of organic clayey silt was uncovered within the tube, a small-scale laboratory vane shear test (LVST) was then performed at constant rate within this thin stratum. Although use- ful in defining the depth of this stratum across the site, in situ piezocone penetration test data (CPTU) were not useful in further quantitatively defining the shear strength characteristics of this stratum due to its being typically only approximately one inch (or so) in thickness.

As indicated previously, the peak undrained shear strengths of this thin, sensitive layer are lower than those of the other paludal clay horizons in the old freshwater marsh and cypress swamp deposits. Values of peak undrained shear strength within this material were found to vary from $s_{u} \approx 200$ to $300 \mathrm{lb} / \mathrm{ft}^{2}$ beneath the full overburden loading under the centerline of the levee embankment to $s_{u} \approx 75$ to $125 \mathrm{lb} / \mathrm{ft}^{2}$ beneath the inboard side levee toe. Fig. 15 shows results from a suite of four of the laboratory vane shear tests performed on the thin "hurricane" stratum, expressed in normalized fashion as shear stress divided by the peak undrained shear strength of each sample $\left(\tau / s_{u}\right)$. Also shown in this figure is a suite of four additional LVST performed on relatively undisturbed samples of the nearby soft gray clays $(\mathrm{CH})$ from slightly lower in the soil profile at this site. As shown in Fig. 15, this thin stratum is more sensitive than the nearby clays; it drops more rapidly to a lower fraction of its peak strength at low levels 


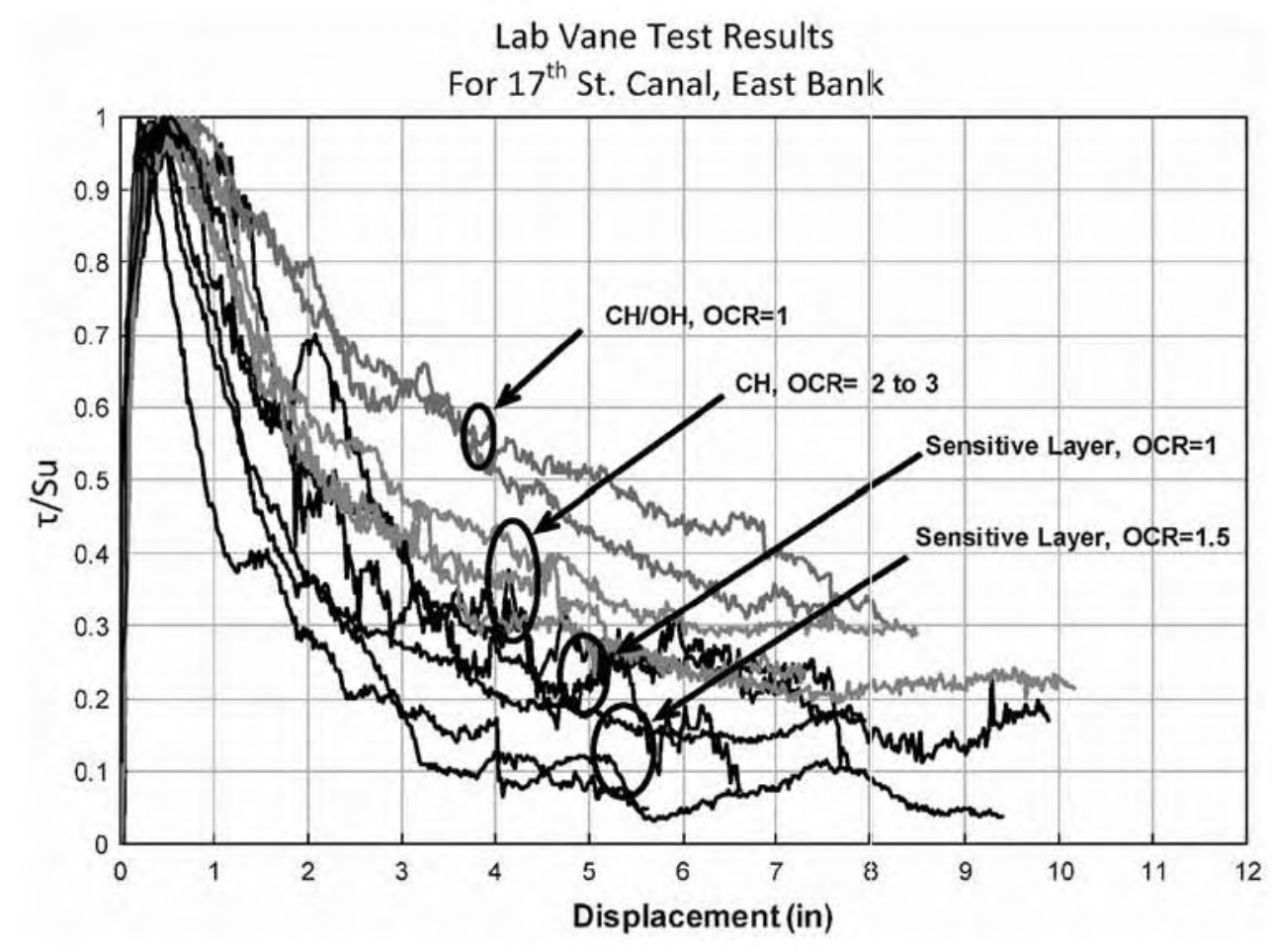

Fig. 15. Plots of shear stress normalized by peak undrained shear strength $\left(\tau / S_{u}\right)$ versus rotational shear displacement from laboratory vane shear tests on both the soft, gray foundation clays $(\mathrm{CH})$ and the thin stratum of sensitive organic clayey silt

of shear displacement. Because this layer is also very thin, and thus prone to essentially full transition to low residual strength at small overall lateral offsets, it represents a very weak and brittle element relative to the overlying and underlying soft soils at this site with regard to potential lateral translational instability. Residual strengths of the material in this thin stratum were found to be very low, typically on the order of $s_{u} \approx 10-40 \mathrm{lb} / \mathrm{ft}^{2}$.

Because of the weak and sensitive nature of this thin stratum, the peak shear strengths measured by this laboratory vane shear testing program were reduced by $15 \%$ to produce the engineering peak shear strengths used in the analyses (to accommodate the effects of strain softening and progressive rupture). Additional reductions were not made for the combined effects of anisotropy and stress path, as this was a structured, flocculated clay deposit at light to moderate overburden. These additional factors (anisotropy and stress path) were judged to be moderate, and because no sample is perfectly undisturbed, these additional factors would be offset somewhat by reductions in the strengths measured in the laboratory due to disturbance effects.

For the finite-element analyses, the Mohr-Coulomb model was used, which does not allow explicit modeling of strain softening. The reduction of shear strengths described above was judged necessary for both limit equilibrium analyses and finiteelement analyses as an approximate treatment of this sensitivity. Subsequent to the ILIT's initial studies (ILIT 2006), additional analyses have now been performed in which the actual (full) peak shear strength and the actual transition from peak to residual strength were modeled explicitly through stepwise changes in the properties as a function of deformation experienced at various locations along the potential failure surface (special treatment of this strain softening, through the reduction of strength in steps), and the results are reported in Seed et al. (in preparation). Comparison between the analyses reported herein (which approximate this effect) and those subsequent analyses that more explicitly model strain softening suggest that using a slightly more severe strain softening/progressive rupture penalty factor of approximately $0.75-0.8$ to approximate the effects of this strain softening would have provided slightly better agreement with the more advanced subsequent analyses. Both sets of analyses appear to agree well with the actual observed field performance of the levee at the 17th Street Canal breach.

\section{Limit Equilibrium and Finite-Element Analyses}

Both conventional limit equilibrium analyses using Spencer's method (Spencer 1967), cross checked against several others, and finite-element analyses, through the strength reduction procedure (Brinkgreve 2007), were performed to evaluate overall stability and displacements as water levels rose within the canal. The results of both types of analyses were in close agreement.

As discussed previously, the soft soil model within PLAXIS was selected to model the soft foundation clays, the transition zone, and the marsh strata. The thin, sensitive critical stratum was modeled with a simpler, nonlinear Mohr-Coulomb model, and undrained shear strengths (modeled as cohesion: "c") were directly input into each element to model the variation of strength as a function of overburden pressure shown in the laboratory vane shear testing. Properties used to model all of these foundation soils thus varied laterally across the finite-element mesh (due to changes in vertical effective stress), and with the exception of the thin critical stratum, they also varied vertically due to the vertically varying OCR profiles as described previously. Detailed descriptions of the parametric modeling are presented in ILIT (2006), and Table 1 presents a summary of parameters modeled in the PLAXIS analyses.

The limit equilibrium method (LEM) analyses for this study 
Table 2. Summary of Soil Shear Strength Parameters Used for Limit Equilibrium Analyses

Stratum name

Upper levee embankment fill

Lower levee embankment fill

Upper marsh, beneath crest

Upper marsh, free field

Thin sensitive layer; beneath crest

Thin sensitive layer; beneath toe

Thin sensitive layer; free field

Soft gray clay $(\mathrm{CH})$

Sand (SC)

\section{Soil model}

Mohr-Coulomb

Mohr-Coulomb

Mohr-Coulomb

Mohr-Coulomb

Mohr-Coulomb

Mohr-Coulomb

Mohr-Coulomb

Mohr-Coulomb

Mohr-Coulomb

$\begin{array}{cc}\begin{array}{c}\text { Shearing } \\ \text { type }\end{array} & \begin{array}{c}\gamma_{\text {sat }} \\ \left(\mathrm{lb} / \mathrm{ft}^{2}\right)\end{array} \\ \text { Undrained } & 115 \\ \text { Undrained } & 95 \\ \text { Undrained } & 80 \\ \text { Undrained } & 80 \\ \text { Undrained } & 85 \\ \text { Undrained } & 85 \\ \text { Undrained } & 85 \\ \text { Undrained } & 95 \\ \text { Drained } & 110\end{array}$

$c$
$\left(\mathrm{lb} / \mathrm{ft}^{2}\right)$
900
600
375
200
240
180
70
Varies $^{\mathrm{a}}$
0

\begin{tabular}{c}
$\varnothing^{\prime}$ \\
0 \\
0 \\
0 \\
0 \\
0 \\
0 \\
0 \\
\hline $33^{\circ}$
\end{tabular}

$\left(s_{u} / p^{\prime}\right)_{N C}$

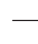

-

$-$

$-$

$-$

-

0.23

- $\lambda$

-

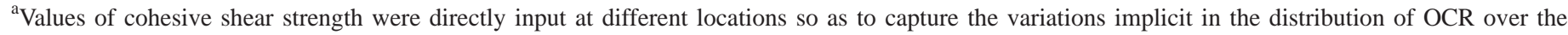
domain, and the SHANSEP parameters shown in the two right-hand columns.

were performed mainly using the program SLOPE/W of the software package GEOSTUDIO (Krahn 2004). Shear strengths modeled in limit equilibrium analyses also varied both laterally and vertically across the problem domain, and were essentially identical to the shear strengths effectively modeled in the finiteelement analyses. Table 2 presents a summary of shear strengths modeled in the limit equilibrium analyses.

Full details of the finite-element analyses are reported in ILIT (2006). Fig. 16 shows relative shear strain levels (shear strain, divided by shear strain to failure, within each of the soils) calculated by these analyses at a canal water level of elevation $+8.5 \mathrm{ft}$ (MSL), which is approximately the water level at which failure appears to have occurred. Fig. 16 shows localization of the shear deformations along a translational sliding surface constrained by the location of the thin, sensitive stratum within the upper marsh deposits.
Interface elements were employed between the sheetpiles and the soils on their outboard sides, and when tension was calculated at these interfaces, the analysis was halted and the mesh was manually altered to allow the sheetpile to separate from the soils in the zone where tension had been calculated. Lateral water pressures were applied to both sides of the newly opened gap. This was iteratively repeated at each canal water level until gap propagation ceased, and then the next incremental rise in canal water levels was introduced and the analysis proceeded. The finiteelement analyses showed that as the canal water level rose to approximately elevation +6.5 to $+7.5 \mathrm{ft}$ (MSL), a tensile gap began to open on the outboard side of the sheetpile curtain, between the sheetpiles and the outboard side half of the earthen levee embankment. Water entered into this gap, and applied additional water pressures against the sheetpile curtain. This, in turn, caused the gap to open rapidly to greater depth with subsequent

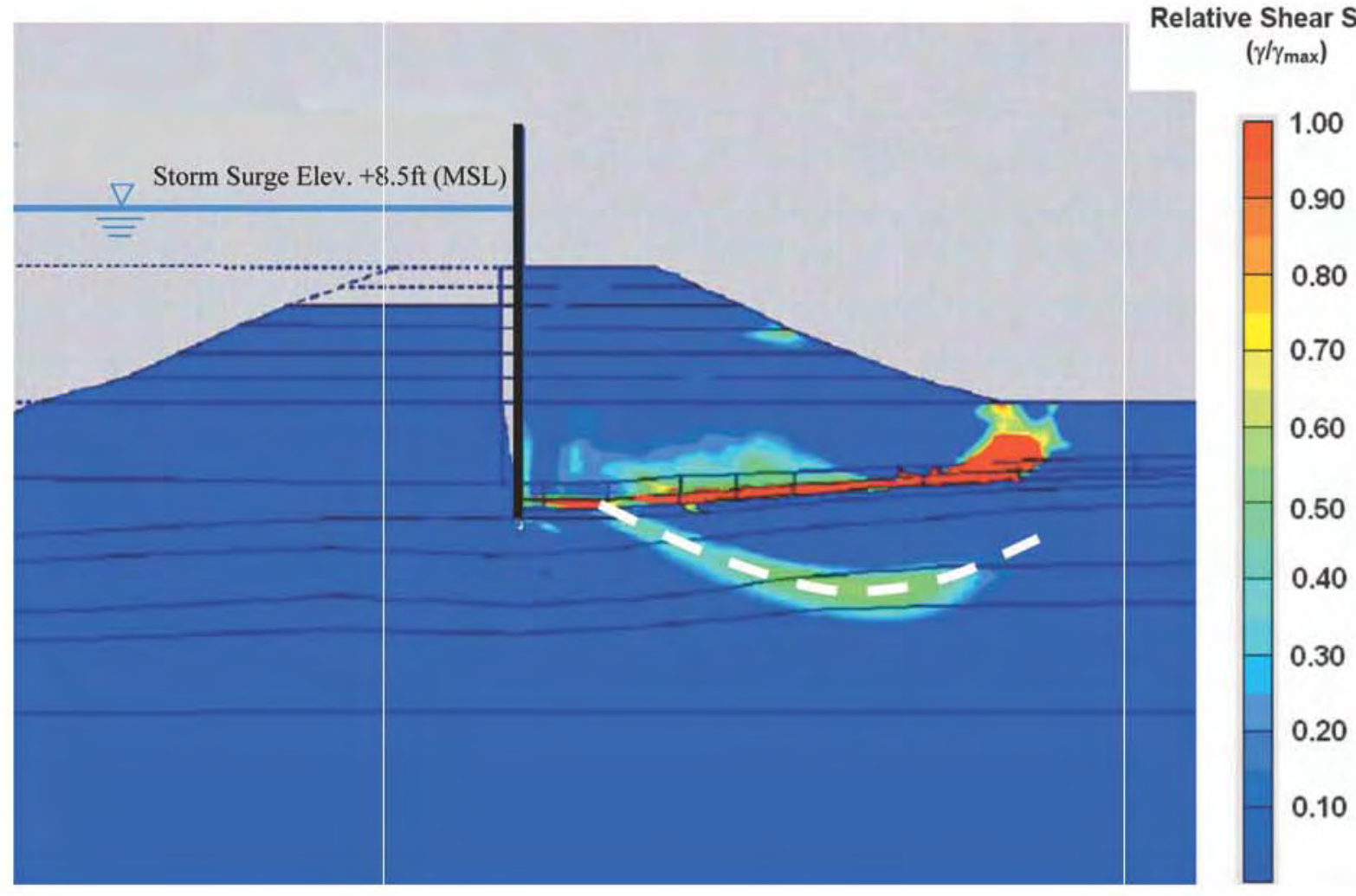

Fig. 16. (Color) Relative shear strain at a storm surge level of elevation $+8.5 \mathrm{ft}$ (MSL) - 17th Street Canal breach site 


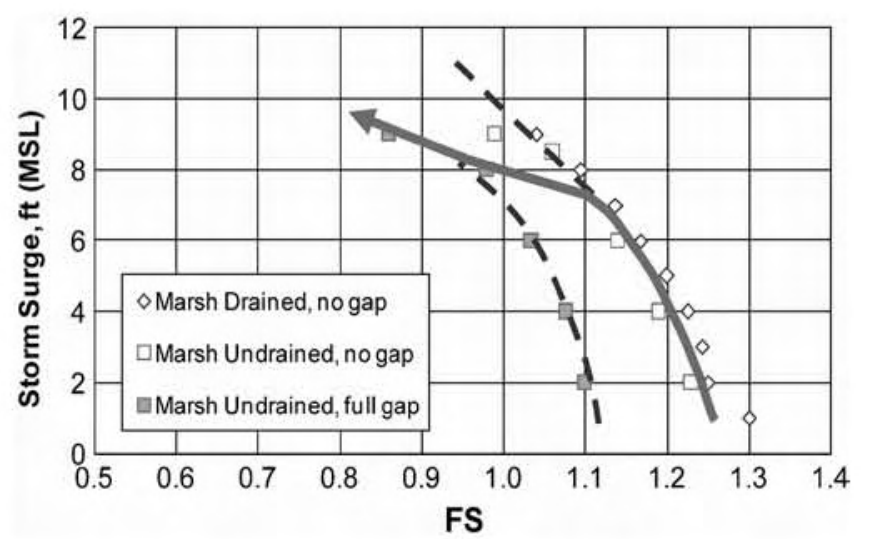

Fig. 17. Evolution of factor of safety versus rising canal water level-17th Street Canal breach site

water level rises, allowing the lateral water forces eventually to be applied to essentially the full depth of the sheetpile curtain.

The development of a water-filled gap on the canal side of the sheetpile had a significantly deleterious effect on overall levee stability. A water-filled gap had been observed in the field at additional failure sites on the London Avenue Canal during the initial post-Katrina forensic visits (Seed et al. 2008b), and was also strongly suggested by the postfailure geometry and conditions at the 17th Street canal breach. Water-filled gapping was, therefore, also modeled in the conventional limit equilibrium method analyses; modeling a water-filled gap to full depth at the outboard side of the sheetpile curtain. Additional limit equilibrium analyses were also performed without this water-filled gap, and the results of those analyses showed significantly higher overall factors of safety (on the order of 15-20\% higher) for the latter stages of storm surge rise within the canal than analyses that included the water-filled gap. The best estimate calculations of factor of safety by means of the conventional limit equilibrium analyses were those that assumed the formation of a water-filled gap fully to the base of the sheetpiles during the latter stages of storm surge rise.

Fig. 17 shows the evolution of factor of safety as water levels rose, based on finite-element analyses. The two sets of symbols on the right (open squares and open diamonds) represent the results of finite-element analyses of two different potential failure mechanisms, both without allowing the formation of a waterfilled gap on the canal side of the sheetpile wall. The "marsh drained" analyses in Fig. 17 represent the consideration of underseepage pressures and potential failure of the marsh stratum directly beneath the thin critical stratum. The marsh undrained analyses represent the potential failure along the thin critical "hurricane" stratum itself. The solid squares to the left are also based on finite-element analyses. The solid squares present results specifically for potential translational failure along the thin critical stratum, and they show the factor of safety if a water-filled gap extends fully to the base of the sheetpile wall throughout the storm surge. Finally, the solid line with an arrow in Fig. 17 is based on sequential (incremental) finite-element analyses modeling the incremental water rise and the corresponding incremental (progressive) gap formation, and thus, shows the actual calculated evolution of conditions as the water-filled gap initially begins to open at a canal water elevation of approximately $+7 \mathrm{ft}$ (MSL) and then opens to progressively greater depths as the canal water level continues to rise. The finite-element analyses showed that this gap should begin to open at a canal water level of approximately elevation $+7 \mathrm{ft}$ (MSL), and that it would develop essentially fully to the base of the sheetpiles very soon thereafter.

Conventional limit equilibrium analyses could not be used to track this progressive evolution of a water-filled gap, but the results of limit equilibrium analyses for both the "gapped" and "ungapped" cases agreed closely with the finite-element results presented in Fig. 17, so that conventional limit equilibrium analyses conservatively assuming that a water-filled gap would eventually develop also served to explain well the observed failure at a water elevation of approximately +7.5 to $+8.5 \mathrm{ft}$, (MSL) (ILIT 2006).

There is relatively good agreement that the failure occurred at a canal water elevation of between about +7.5 to $+8.5 \mathrm{ft}$ (MSL) (e.g., ILIT 2006; Van Heerden et al. 2006; IPET 2007). Water marks at locations along the Lake Pontchartrain shoreline in the vicinity of the head of the 17th Street canal that were not affected by waves indicate that the water level along the south shore of Lake Pontchartrain reached a maximum surge elevation of +9 to $+9.5 \mathrm{ft}$ (MSL) at the mouth of the 17th Street canal, just to the north of the failure site (Van Heerden et al. 2006; IPET 2007). There was a significant amount of wooden debris generated by storm waves and their destruction of docks and other exposed facilities along the south shore of the lake, however, and this debris was drawn into the narrow openings beneath the Hammond Highway Bridge across the north end of the 17th Street canal as storm surge waters passed into the canal. Therefore, it is not clear exactly what fraction of the full storm rise of +9 to $+9.5 \mathrm{ft}$ (MSL) from the adjacent lake was fully transmitted through this potential obstruction/constriction and into the canal.

Actual storm surge levels were measured and manually recorded at $30 \mathrm{~min}$ intervals during the storm at the extreme south end of the canal, at the large pumping station, and these showed that water levels at the south end of the canal rose to elevation +7.5 ft (MSL) by about 5:00 a.m., but that between 6:00 and 6:30 a.m. they temporarily stopped rising and even briefly dipped a bit to as low as $+6.5 \mathrm{ft}$ (MSL). They then resumed their rise, reachieving an elevation of nearly $+7 \mathrm{ft}$ (MSL) but exhibiting a series of intermittent fluctuations and small drops. At some point shortly after 9:00 a.m., they dropped rapidly back to less than $+2 \mathrm{ft}$ (MSL) and never rose again to levels much higher than that. It is not clear whether the half-hourly recordings fully captured the peak water level. Based on eyewitness testimony, and a videotape shot by a fire crew from the adjacent Jefferson Parish (that did not record the actual major breach occurring, but captured its immediate aftermath), it is inferred that the I-wall moved laterally and opened a V-shaped notch between two of the concrete I-wall panels (as reported by an eyewitness) at about 6:00 a.m. That would likely correspond to the first minor (and temporary) dip in surge rise observed at the south end of the canal. The main breach subsequently occurred at about 9:00 a.m., producing the rapid and permanent lowering of storm surge water levels within the canal. Given the length of the canal (approximately 2 miles), water levels at the north end of the canal may have differed slightly from those observed at the pumping station at the south end.

These hand recorded stage observations, coupled with the eyewitness testimony (IPET 2007), would appear to suggest that sufficient wall displacement had occurred at about 6:00 a.m. as to produce separation between two adjacent concrete I-wall panels [at a canal water elevation of approximately $+7.5 \mathrm{ft}(\mathrm{MSL})$ at the eventual breach site], and that the main breach and lateral translational stability failure occurred at about 9:00 a.m. at a canal water elevation of approximately +7.5 to $+8 \mathrm{ft}(\mathrm{MSL})$ at the breach site. Thus, the analyses performed (both limit equilibrium, and finite-element analyses) showing that failure would have been 
expected to occur at a canal water elevation of approximately +7.5 to $+8.5 \mathrm{ft}$ (MSL) are in good agreement with observed field behavior (ILIT 2006). Similarly, the displacements calculated by the finite-element analyses showing that significant gapping and significant lateral wall displacements would begin to occur at canal water elevations of approximately $+7 \mathrm{ft}$ (MSL) also appear to be in good agreement with the apparent field performance [including the occurrence of sufficient displacements as to produce a separation between two adjacent concrete I-wall panels at a canal water surge elevation of approximately elevation +7.5 ft (MSL)].

As an aside, the limit equilibrium analyses for this study were performed mainly using the program SLOPE/W. This code has a programming error that results in an incorrect numerical treatment of conditions associated with a water-filled crack at the heel of a failure mass for undrained analysis conditions; a problem that became apparent when the initial results of limit equilibrium analyses were compared with the results of finite element analyses and hand calculations. Similar problems were found in some other slope stability programs such as UTEXAS4 (Wright 1999). This problem has now been fixed in UTEXAS4 (Wright, personal communication), and it is expected that it will be rectified in other codes. In the interim, the solution to this problem is to delete the soil mass to the far side of the crack (on the canal side of the "water-filled gap" at the outboard side of the sheetpile curtains for these levee section analyses), and to manually apply the lateral water forces acting against the resulting exposed vertical face.

\section{Examination of an Alternate Hypothesis for the Failure}

Fig. 16 clearly shows the localization of shear strains (and shear failure) along the thin stratum of weak, sensitive organic silty clay silt at shallow depth beneath the levee embankment, just at the start of incipient (large translational) full lateral instability. Fig. 16 also shows a second potential competing failure mechanism that is partially developed at this same canal water elevation [elevation+8.5 ft (MSL)]. This second mechanism, highlighted by a dashed white line superimposed in Fig. 16, is a deeper semirotational failure through the underlying soft gray foundation clays. This deeper, rotational mechanism has been identified as the critical mechanism by the IPET investigation (IPET 2006, 2007), and the second most critical mechanism by our ILIT investigation (ILIT 2006).

Fig. 18 shows the most critical failure surfaces for these two competing potential modes of failure, as well as the resulting geometries arising from each failure mechanism, using our interpretations of foundation soil strengths and a conservatively estimated maximum canal water elevation of $+8.5 \mathrm{ft}$ (MSL). Fig. 18(a) shows the shallow critical failure surface along the thin, sensitive hurricane stratum and the corresponding factor of safety for a canal water elevation of $+8.5 \mathrm{ft}$ (MSL) as calculated by limit equilibrium analyses (Spencer's method), while Fig. 18(b) shows the lateral translational failure mechanism observed in the field. Similarly, Fig. 18(c) shows the deeper critical rotational failure mode, and Fig. 18(d) shows the likely resulting movements in the field compatible with this more rotational failure mode.

Based on our analyses, the deeper rotational failure mode has a slightly higher factor of safety (FS) [i.e., see Fig. 18(c), wherein the most critical LEM surface has FS=1.12] than the translational mode on the critical thin, sensitive stratum. Based on our interpretations of the data and geometries, the deeper rotational mode has factors of safety that are approximately $29-34 \%$ higher, re- spectively, based on finite-element and limit equilibrium analyses than the critical mode of lateral translation along the thin critical stratum of sensitive organic clay [i.e., see Fig. 18(a), wherein the most critical LEM surface has $\mathrm{FS}=0.83$ at this same water elevation].

The deeper rotational failure mechanism has a relatively low factor of safety (i.e., $F S=1.12$ ), and it can also approximately serve to explain the first toe exit scarp feature [Toe Scarp 1 of Fig. 4(b)]. But this second (deeper, rotational) potential failure mode cannot explain other critically important observed field phenomena as shown in Fig. 4, and illustrated by the deformation modes resulting from these two failure mechanisms as shown in Figs. 18(b and d), including: (1) the very large lateral translation $(\sim 49 \mathrm{ft})$ of the intact inboard half of the levee embankment section (the deeper rotational mechanism provides for only very limited lateral displacement of the levee crest section, and of the crest fence); (2) the lack of rotation of the displaced earthen embankment section with its horizontal crest, and nearly vertical crest fence after displacement; and (3) the multiple exiting toe scarps (including Scarps 2 and 3) that extend well over $100 \mathrm{ft}$ to the inboard side of the original location of the landside levee toe.

Although the deeper, rotational failure mechanism does not explain the physical evidence at this breach site, it should be noted that this deeper rotational failure would have likely occurred if the canal water elevation had risen to approximately +10 to $+10.5 \mathrm{ft}$ (MSL), and if the thin stratum of weak and sensitive organic clayey silt at shallow depth had not been present to provide an even more critical failure mechanism. Accordingly, this deeper rotational failure mechanism would also have resulted in failure to achieve the targeted factor of safety of FS $\geq 1.3$ for the much higher targeted design canal water level elevation [a targeted design water elevation of $+14.5 \mathrm{ft}(\mathrm{MSL})]$.

\section{Discussion of Lessons Learned from the Failure}

There were several issues that together led to the failure and breach on the 17th Street canal. No single lapse by itself was the fatal one; but there were a number of individual lapses that could by themselves have likely prevented the failure if they had been recognized and corrected. Other issues and/or problems worked together, in conjunction, to contribute to this failure.

As discussed in the companion paper by Rogers et al. (2008), the USACE had battled for authorization to construct storm gates at the north ends of the three drainage canals to prevent storm surges from entering these canals and threatening potential flooding of the Orleans East Bank protected basin. Local interests, focused in part on concerns with regard to pumping of rainfall out through these canals, appeared to thwart the USACE efforts in this regard. The Fifth U.S. District Court ruled against the USACE plans for tidal gates at the mouths of the drainage canals in December of 1977 on the basis that the USACE had failed to consider other alternatives. Instead, the plan to raise floodwalls atop the levees lining the edges of the drainage canals was eventually adopted (Wooley and Shabman 2007). Construction of the proposed gates would have been a good engineering solution, and would have prevented storm surge rise within the canal during this event. In the wake of Hurricane Katrina, the USACE has received permission and closed off the north ends of these three drainage canals, and has installed additional banks of pumps at the north ends of the three drainage canals to pump water over these drainage canal closures and out into Lake Pontchartrain.

A second policy decision, made jointly by local agencies and 

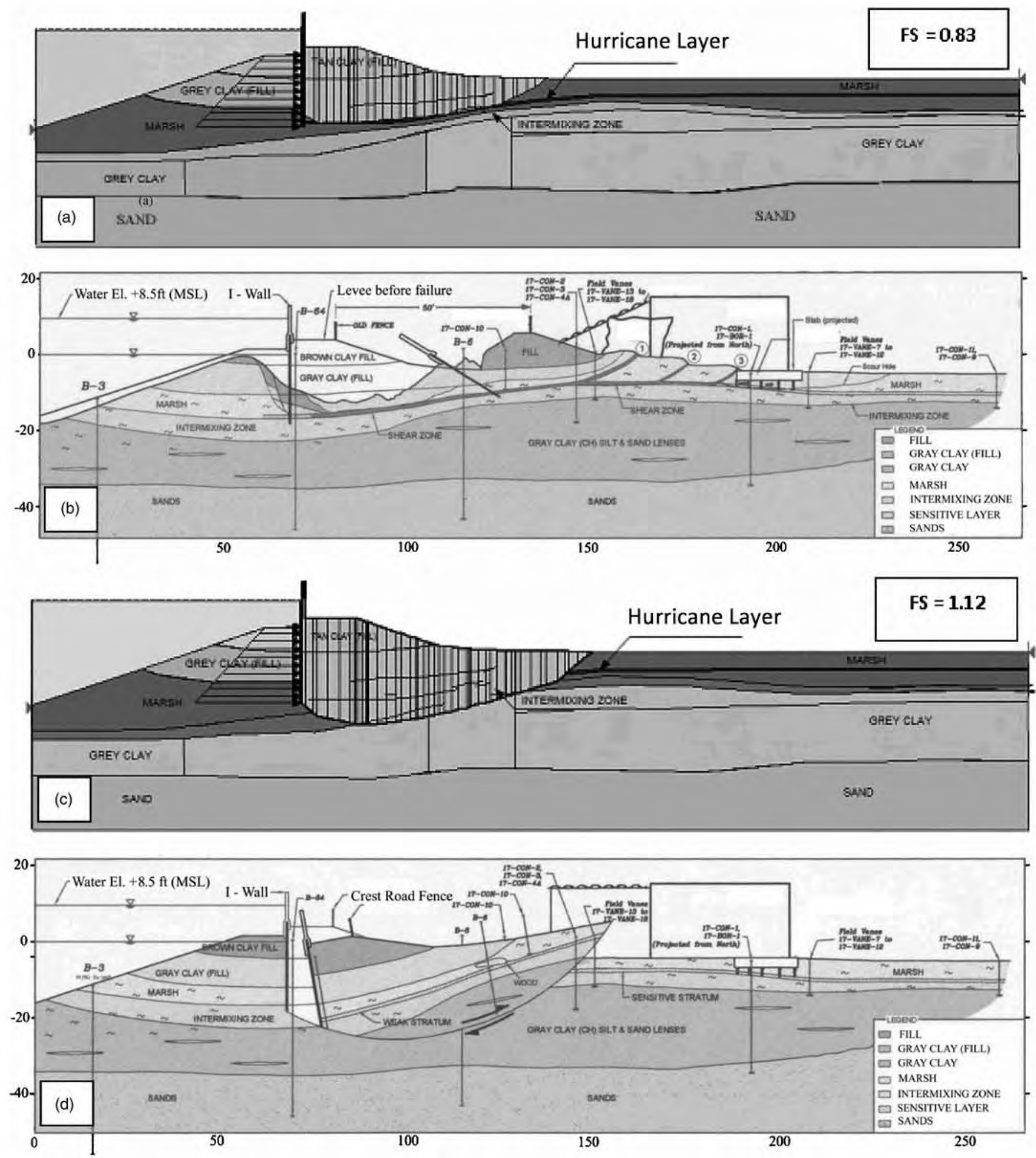

Fig. 18. Stability analysis and schematic representation of the potential failure mechanisms at the 17 th Street Canal breach section with storm surge at Elev. +8.5 feet (MSL) and with fully developed crack at the outboard side of the sheetpile/floodwall: (a) LEM stability analysis of shallow transitional failure; (b) actual observed failure mechanism (i.e., translational failure along the sensitive clay layer within the marsh deposits); (c) LEM stability analysis of deep rotational failure; and (d) schematic representation of the deep rotational failure mechanism through the deeper soft gray clays 
by Congress, was the decision not to purchase additional land adjacent to the drainage canals as part of the effort to raise the canal levees (and flood walls) to provide protection for higher storm surge levels in the wake of the disastrous flooding of much of New Orleans by Hurricane Betsy in 1965. Adjacent homes had been built up closely against the canal levees because these lots were subdivided in the 1910's and 1920's at a time where the land surface was $6-8.5 \mathrm{ft}$ higher than present, and more than 40 years before they were actually developed. Levee boards judged that the cost of purchasing additional right of way to permit widening of the earthen levee embankments would have been excessive and that popular public sentiment opposed such drastic action (Rogers 2008). It was decided instead, to raise sheetpile-supported concrete floodwalls at the crests of the levees, keeping the old earthen levees (constructed between 1833 and 1878) within their existing footprints (Wooley and Shabman 2007; ILIT 2006). That was a more challenging approach, because enlarged (and widened) earthen levees would have been more effective in supporting the floodwalls and the increased lateral water forces that would eventually be exerted against these floodwalls.

Recognizing the difficulties associated with the raising of these floodwalls on the crests of the existing, relatively narrow earthen levees, the local New Orleans District of the USACE performed a test of key components this type of floodwall design in the nearby Atchafalaya River basin. That project, referred to as the E99 test section, involved the construction of a sheetpile/ floodwall (I-wall) section inboard of an existing levee along the Atchafalaya River atop foundation soils that were similar to those present along portions of the 17th Street canal. A sheetpile cofferdam was constructed to allow progressively higher water levels to laterally load the E99 sheetpile/floodwall section. The test section's sheetpile wall was brought to a condition estimated to represent an incipient failure. During this field test, the sheetpile wall appeared to rotate as an essentially rigid unit. This rotation should have opened a gap between the sheetpiles and the adjacent compacted earth, but the E-99 test was stopped short of a full stability failure, and there is no record of a gap being observed during testing. Because the wall and the soil in front of the wall were covered with a plastic membrane, which was in turn filled with water, it would have been difficult to observe a gap opening even if it did. Several follow-on analytical studies were performed to evaluate the E-99 test section (e.g., Jackson 1988; Oner et al. 1988; 1997a,b; Leavall et al. 1989), but the possibility of a waterfilled gap forming on the canal-side of the sheetpile/floodwall was not considered in the design analyses of these I-wall sections (USACE 1990). It appears that an opportunity to identify a potentially important failure mechanism was missed, due in part to the membrane that was employed to ensure water-tightness during the test.

The USACE generally requires a minimum FS of 1.3 for evaluating potential lateral levee embankment instability for transient loadings, such as a relatively short duration hurricaneinduced storm surge. The FS $\geq 1.3$ criterion has evolved historically, and dates back to an earlier era when most levees protected primarily rural, agricultural lands; not major urban areas with populations of hundreds of thousands of people. Additionally, the transient loading of hurricane-induced storm surges represents the primary loading condition for which these levees were built. Given the high stakes in terms of population at risk, it is our view that this factor of safety provided too little margin for errors, omissions, inherent geotechnical uncertainty, or for unusual geological conditions that might go undiscovered at any point along many miles of levee frontage by relatively sparse site investigations (ILIT 2006).

There were also a number of geotechnical lapses that contributed to this failure. There appears to have been under-appreciation of the importance of local geological nuances in the design process. Field investigations (e.g., drilling, sampling, and testing) were often performed as separate operations, disjoint from the subsequent analyses and design operations. Integration of geological and geotechnical data, verification of field observations by experienced engineers and geologists, and careful evaluation of abnormalities are essential elements to designing a water protection system that spans such difficult and varied geology. For example, during these forensic investigations, the critical thin stratum at this site was only discovered after questioning why there was such a high rate of nonretrieval of samples at the same depth at the site. Of course, after a failure, it is easier to identify such a layer, but a careful study of the local geology and reevaluation of the sampling success at the site would have likely identified the potential for weak thin layers of sensitive clays in this environment (e.g., Leonards 1982). Based on the observations from the initial field forensics, the ILIT field sampling team was looking for a potential unusually weak stratum at a depth of approximately $5-10 \mathrm{ft}$ beneath the inboard levee toe that might have led to a translational lateral stability failure. The team was aware of the potential for these types of "hurricane" strata, and the likelihood that they would be covered by organic debris from a (saltwater-induced) posthurricane die off. Based on the preKatrina borings and data, and the obvious gap in data at the depth of this critical stratum caused suspicion.

This serves as an important pair of lessons for the geotechnical profession: (1) it points up the continuing importance of geological engineering and engineering geology; and (2) it points up the importance of fully integrating all phases of engineering design (and maintenance), including site investigation, laboratory testing, engineering geology, geotechnical analysis, and engineering design. Unfortunately, the pressures of modern practice appear to be increasingly causing these functions to be performed separately, and often by sub-teams and individuals who are not adequately interactive with the overall process.

Additionally, the methods used during the original design studies to analyze the critical potential failure mode of lateral embankment instability were outdated. Despite the widespread availability of more advanced methods, the local district had continued to perform these analyses using the "method of planes," which is essentially a three-wedge force equilibrium method in which a central block is sandwiched between an active wedge and a passive wedge (USACE 1990). The method requires a horizontal sliding plane beneath the base of the central block. Side forces at the vertical boundaries between the three blocks include no shear tractions, resulting in horizontal side forces on these interblock boundaries, so the method provides a moderately conservative assessment of lateral stability for situations to which it can be suitably applied (IPET 2007). Armed with relatively sparse site investigation data, the common local practice for Federal project levees in the region was to assume laterally horizontal stratigraphy; permitting the use of the simplistic method of planes. This was further exacerbated by the assumption that the local stratigraphy of the marsh types of deposits tended to be relatively horizontally layered.

The local stratigraphy, however, was not horizontally layered. Drainage features, that subsequently infilled with new accreted sediments, led to local slopes at subsurface soil strata boundaries. In addition, consolidation of relatively soft, compressible sedi- 
ments under the loads imposed by the constructed earthen levee embankments also produced nonlevel soil strata boundaries. As discussed in the companion papers (Seed et al. 2008a,b), relatively subtle changes in the slopes of soil strata boundaries at a number of the most important failure sites during Hurricane Katrina were the difference between satisfactory and unsatisfactory performance of the levees at those sites. As discussed in the companion paper on regional and local geology by Rogers et al. (2008), localized nonlevel stratigraphy should have been anticipated. More modern, flexible, and accurate methods of limit equilibrium analysis were available that could have been used to search for potentially more critical failure surfaces (IPET 2007).

The processing of available data and the selection of soil shear strength values for design are another set of geotechnical issues that warrant consideration. Fig. 19 shows a summary of available (pre-Katrina) shear strength data, and the shear strength versus depth profile (the solid line) that was eventually selected and used during the original design studies along the levee frontage section that included the 17th Street canal breach site. The datum used in Fig. 19 is the archaic "cairo datum," which is offset by approximately $+20 \mathrm{ft}(\mathrm{MSL})$. One potential problem is attributed to the "averaging" of data across large longitudinal lateral distances (i.e., along the levee) and lateral extrapolation away from the crest of the levee as discussed in the following paragraphs.

A second issue here was the judgmental interpretation of the available strength data. As shown in Fig. 19, the shear strength profile eventually used for the original design analyses is difficult to justify based on the available strength data as the strength profile selected clearly falls on the high side of a majority of the data in the critical elevation range of between -5 and $-30 \mathrm{ft}$ (MSL). Fig. 19 has been annotated to show: (1) the depth range within which the thin, critical organic silty clay stratum that became the eventual failure plane is located; and (2) the principal depth range of interest for the second most critical potential failure mode, i.e., the deeper rotational failure through the soft, gray clays. As shown in this Fig. 19, there is a disturbing "gap" in shear strength data at the depth of the upper, critical failure plane. The earliest of the original site investigation borings resulted in a number of "nonrecovered" samples in adjacent boreholes at this depth, and the lack of data at this critical depth continued to persist through the design process. Equally daunting is the clear tendency of the shear strengths selected for design in the lower depth range, representative of the critical depth for deeper rotational failure through the soft gray clays, to fall below the strength profile selected for design (which is indicated by the heavy solid line in Fig. 19), as was also noted in the IPET investigation (IPET 2007). This particular observation is more critical considering that the strength profile (derived primarily from UUTX tests) was not corrected to account for the more realistic simple shear mechanism that will likely dominate the response.

This apparent overestimation of strengths was then worsened by extrapolating them laterally towards regions in which the actual strengths would be even lower due to lesser overburden stresses. The shear strengths shown as data points in Fig. 19 were nearly all based on samples recovered from beneath the centers of the earthen levee sections; locations which had the highest levels of overburden stress due to the weights of the overlying embankments. These strengths were then extrapolated laterally, and were used beneath the inboard (landside) toes of the levee embankments, and even beneath the bare ground to the inboard side of the levee toes; regions with far lesser effective vertical overburden stresses. The use of shear strengths measured from samples obtained from beneath the centers of the levee embankments would, of course, be expected to systematically overestimate shear strengths beneath and inboard of the levee toes, and it is the regions beneath and inboard side levee toes that are most critical for the types of lateral translational stability that eventually produced the breach and failure at this site. The work of Ladd and Foott (1974), and Foott and Ladd (1977) in working with mineralogically similar clays at the nearby Atchafalaya River levees was pivotal in establishing the SHANSEP-type methods for engineering assessment of these types of strengths (and the systematic effects of effective consolidation stress and OCR on these strengths), and it was unfortunate that these important principles were not employed in the design analyses for this breached section.

\section{Conclusions}

At the 17th Street canal breach site, a key lesson is the continuing importance of the role of engineering geology, and the importance of the local geology and subtle geological nuances. The presence of the thin, highly sensitive "hurricane" layer of organic silty clay that became the critical shear surface for the lateral translational failure that eventually occured went undetected through the initial design investigations and some postfailure investigations. The potential existence and causes of these types of strata (which are produced by previous hurricanes) and the likelihood that they would be overlain and obscured by leaves and twigs and other organic detritus (from the same causative hurricane) are salient features of this geologic region (Kolb and Van Lopik 1958). With poor sample recovery from conventional soil borings coupled with CPTU profiling, there were multiple indications that such a stratum might be present at this site. Yet it was missed. This important failure may serve to help bring a renewed appreciation for the continuing importance of geological engineering and the potentially dangerous effects of thin layers of weak sensitive materials (e.g., Leonards 1982).

At this site, and at many of the other sites discussed in the companion papers (including sites at which failures occurred and sites where levees performed successfully), another important lesson was the high degree to which the investigation was able to match analytical findings with observed field performance; even for cases where the differences in geometry, stratigraphy, and loads between non-failure and failure sites were relatively minor. Both conventional limit equilibrium analyses, as well as more advanced finite-element analyses, agreed closely with the observed field performance if accurate material parameters were used.

However, the analyses need to be a part of a suitably integrated study including: (1) fieldwork; (2) laboratory testing; (3) analysis and design; (4) construction; and (5) operation and maintenance. It was the integration of the various elements of this process that led to the positive results of this forensic study. And, it may be argued that failure to fully integrate these various activities contributed to the initial failure. This case study thus serves to emphasize the need to integrate fully all of these stages or elements of the overall engineering process; both for design studies and for forensic studies. This stands in some contrast to current trends in practice, in which these are increasingly routinely treated as disparate project elements, performed by different personnel or teams, and often without optimal levels of coordination and cross communication (and feedback) between these efforts and teams.

Important lessons to be noted for forensic studies include the 
STA. $252+T 0$ TO STA. $635+00$

SHEAA STRENGTH

TONS / SQ.FT.

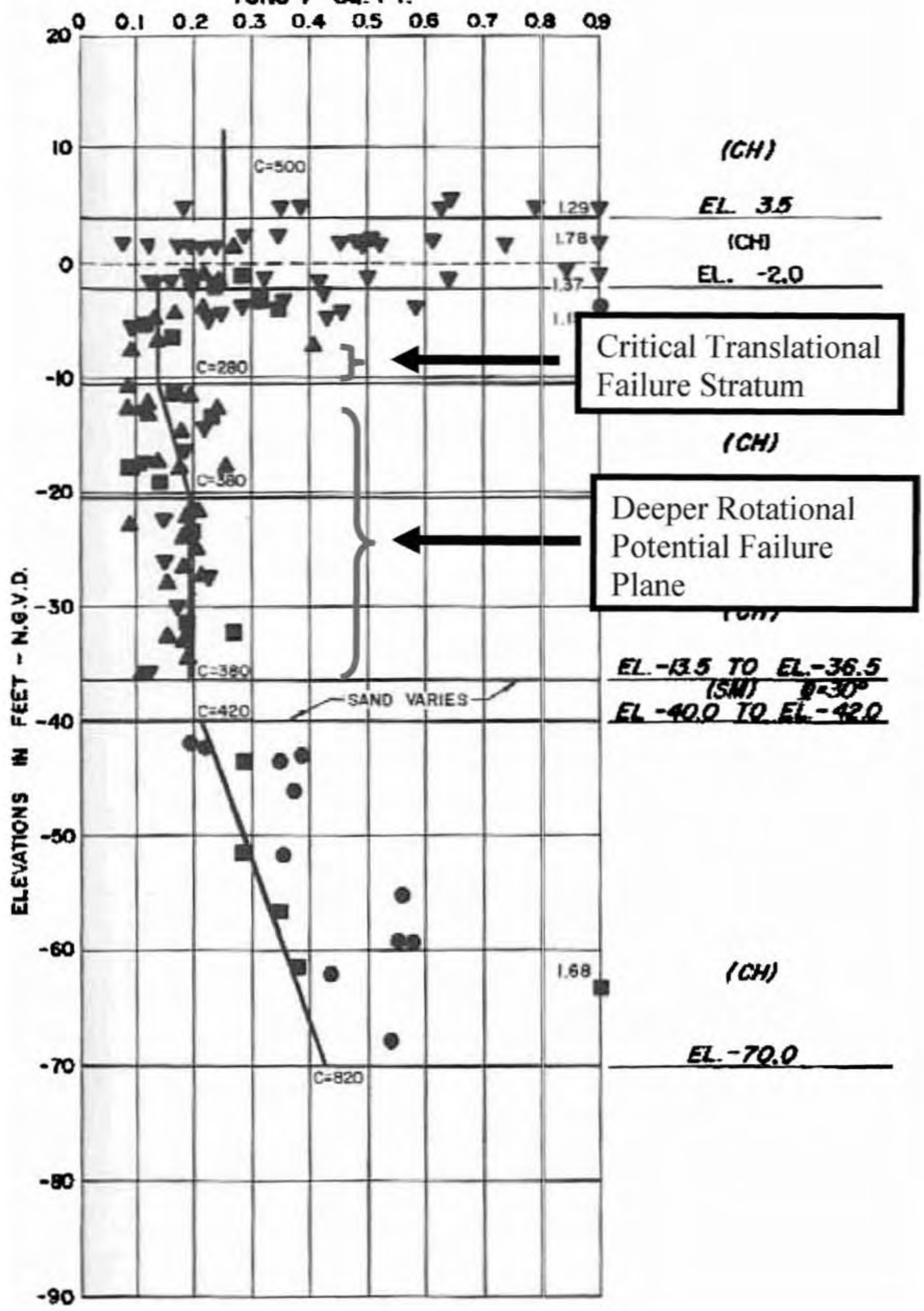

Fig. 19. Shear strength profile used in original design analyses: 17th Street Canal breach section (adapted from USACE 1990) 
need to consider all data and observations, and all potential failure modes, and to test evolving hypotheses as thoroughly as possible against all available field observations. There were two potential failure modes of nearly similar fragility at this site; and both modes would appear to provide potentially feasible explanations of the first toe scarp observed [i.e., Toe Scarp 1 in Figs. 4(b) and 18(a)]. The deeper, semirotational failure mode cannot, however, suitably explain a number of other important field observations, including: (1) the large lateral displacement of the central portion of the levee embankment section; (2) Toe Scarps 2 and 3 farther to the inboard side of the laterally displaced intact levee section; and (3) the lack of rotation of the relatively intact, displaced levee embankment section. Only one potential failure mechanism, lateral translational failure along a shallow, weak and/or sensitive soil layer can satisfactorily explain all of these features. In fact, it was primarily the combined post-failure field observations of apparent lack of rotation accompanying the large lateral translation of the levee section that led the ILIT investigators to look for an unusually weak, sensitive stratum occurring at relatively shallow depth beneath the inboard-side levee toe.

There were also a number of decisions during the original design process that contributed to this failure. These included decisions: (1) to disallow the construction of storm gates at the northern ends of the drainage canals; (2) not to purchase additional land to provide sufficient right of way as to permit widening of the earthen levee embankments; and (3) the use of a low required minimum factor of safety of only 1.3 for the transient loading conditions represented by relatively short-duration hurricane-induced surges in canal water elevations. It is judged that this FS was too low for levee systems protecting urban populations. It was too low for the principal loading condition for which the levees were conceived (i.e., hurricane-induced storm surges), and it provided an insufficient margin for any oversights, uncertainty, or geological anomalies not adequately discovered or characterized by the site investigations and design analyses.

A number of engineering problems also contributed to this failure, including: (1) failure to notice the thin, sensitive stratum of organic clayey silt that became the critical sliding surface for this failure, despite evidence from multiple nonrecovered samples that something unusual existed at that depth; (2) the continued use of an outdated stability analysis procedure (i.e., the method of planes) that was unable to deal adequately with nonhorizontal soil layering; (3) assumption of level soil layering (stratigraphy); (4) extrapolation and averaging of soil shear strength data across excessive lateral distances; (5) optimistic interpretation of some of the available shear strength data and lack of correction for different shear mechanism (i.e., simple shear rather than triaxial conditions); (6) failure to recognize and fully incorporate the effects of effective overburden stress (and OCR) on soil shear strengths, so that strengths evaluated beneath the full weight of the central levee embankment were taken as being also representative of the lower stress regions beneath the levee toes (and inboard of the levee toes); and (7) failure to include consideration of the likely effects of the potential formation of a water-filled crack on the outboard-side of the sheetpile curtain.

No single factor among all of these can be singled out as the most important. Correction of any of a number of these factors, including policy decisions and geologic/engineering factors and judgments, might have prevented this failure. Other factors served, in combination, to contribute jointly to this failure. It is now incumbent upon the profession to learn the lessons offered by the Katrina tragedy, and to ensure that these types of failures are not repeated.

\section{Acknowledgments}

The studies reported herein would not have been possible without the generous help of many individuals and organizations. A moredetailed and extensive acknowledgement is presented in the first of the companion papers and for the sake of brevity is not repeated here. This project was supported, in large part, by the National Science Foundation under Grant Nos. CMS-0413327 and CMS-0611632. Any opinions, findings, and conclusions or recommendations expressed in this material are those of the writers and do not necessarily reflect the views of the NSF. Additional support was provided by the Center for Information Technology Research in the Service of Society at the University of California at Berkeley. In addition, several senior members of the investigation team contributed from their own discretionary resources. All of this support is gratefully acknowledged.

\section{References}

Brinkgreve, R. (2007). PLAXIS 2D. Version 8.5 finite-element code for soil and rock analyses: Complete set of manuals, R. Brinkgreve, ed., Balkema, Rotterdam, The Netherlands.

Chirapuntu, S., and Duncan, J. M. (1975). "The role of fill strength in the stability of embankments on soft clay foundations." Final Rep. Contract S-76-6, Univ. of California at Berkeley, Berkeley, Calif.

DeGroot, D. J., Poirier, S. E., and Landon, M. M. (2005). "Sample disturbance-Soft clays." Studia Geotech. Mech., XXVII(3-4), 91105.

Foott, R., and Ladd, C. C. (1977). "Behavior of Atchafalaya levees during construction." Geotechnique, 27(2), 137-160.

Independent Levee Investigation Team (ILIT). (2006). "Investigation of the performance of the New Orleans regional flood protection systems during Hurricane Katrina." Final Rep., 〈http://www.ce.berkeley.edu/ $\sim$ new_orleans/> (July 31, 2006).

Interagency Performance Evaluation Task Force (IPET). (2006). "Performance evaluation of the New Orleans and southwest Louisiana hurricane protection system.” Draft Final Rep., 〈https://ipet.wes.army.mil/> (June 1, 2006).

Interagency Performance Evaluation Task Force (IPET). (2007). "Performance evaluation of the New Orleans and southwest Louisiana hurricane protection system." Final Rep., 〈https://ipet.wes.army.mil/> (November 2007).

Jackson, R. B. (1988). "E99 sheet pile wall field load test report." Technical Rep. No. 1, U.S. Army Engineer Division, Lower Mississippi Valley, Vicksburg, Miss.

Karlsrud, K., Lunne, T., and Brattlien, K. (1996). "Improved CPTU interpretations based on block samples." Proc., Nordic Geotechnical Conf., Vol. I, Reykjavik, 195-201.

Kaufman, R., and Weaver, F. (1967). "Stability of Atchafalaya levees." $J$. Soil Mech. and Found. Div., 93(4), 157-176.

Kolb, C. R., and Van Lopik, J. R. (1958). "Geology of the Mississippi River deltaic plain, southern Louisiana." Technical Rep. No. 3-483, U.S. Army Engineer Waterways Experiment Station, Vicksburg, Miss.

Krahn, J. (2004). SLOPE/W: Complete Set of Manuals, J. Krahn, ed., Calgary, Alta., Canada.

Ladd, C. C., and DeGroot, D. (2003). "Recommended practice for soft ground site characterization." Proc., 12th Panamerican Conf. on Soil Mechanics and Geotechnical Engineering, Vol I, MIT, Cambridge, Mass., 3-57.

Ladd, C. C., and Foott, R. (1974) "A new design procedure for stability of soft clays.” J. Geotech. Engrg. Div., 100(7), 763-786.

Leavall, D. A., Peters, J. F., Edris, E. V., and Holmes, T. L. (1989). "Development of finite-element-based design procedure for sheet-pile walls." Technical Rep. GL-89-14, Waterways Experiment Station, U.S. Army Corps of Engineers, Vicksburg, Miss. 
Leonards, G. A. (1982). "Investigation of failures." J. Geotech. Engrg. Div., 108(2), 222-293.

Lunne, T., Berre, T., and Strandvik, S. (1985) "Engineering use of piezocone data in North Sea clays." Proc., 11th Int. Conf. on Soil Mechanics and Foundation Engineering, Vol. II, San Francisco, Balkema, Rotterdam, The Netherlands, 907-912.

Mayne, P. W., and Mitchell, J. K. (1988). "Profiling of overconsolidation ratio in clays by field vane." Can. Geotech. J., 25(1), 150-157.

Oner, M., Dawkins, W. P., Hallal, I., and Lai, C. C. (1988). "Development of a new method for soil structure interaction analysis of floodwalls." Rep., Waterways Experiment Station, U.S. Army Corps of Engineers, Vicksburg, Miss.

Oner, M., Dawkins, W. P., Mosher, R., and Hallal, I. (1997a) "Soilstructure interaction effects in floodwalls." Electron. J. Geotech. Eng., 2, 〈http//:www.ejge.com/index_ejge.htm $\rangle$.

Oner, M., Dawkins, W. P., and Mosher, R. (1997b). "Shear ring method for soil-structure interaction analysis in floodwalls." Electron. J. Geotech. Eng., 2, 〈http//:www.ejge.com/index_ejge.htm $\rangle.$.

Pestana, J. M., Whittle, A. J., and Gens, A. (2002). "Evaluation of a constitutive model for clays and sands. Part II. Clay behavior." Int. J. Numer. Analyt. Meth. Geomech., 26(9), 1123-1146.

Rogers, J. D. (2008). "Development of the New Orleans flood protection system prior to Hurricane Katrina." J. Geotech. Geoenviron. Eng., 134(5), 602-617.

Rogers, J. D., Boutwell, G. P., Schmitz, D. W., Karadeniz, D., Watkins, C. M., Athanasopoulos-Zekkos, A., and Cobos-Roa, D. (2008). "Geologic conditions underlying the 2005 17th Street canal levee failure in New Orleans." J. Geotech. Geoenviron. Eng., 134(5), 583-601.
Seed, R. B., et al. (2008a). "New Orleans and hurricane Katrina. Part II: Central region and the lower Ninth Ward." J. Geotech. Geoenviron. Eng., 134(5), 718-739.

Seed, R. B., et al. (2008b) "New Orleans and Hurricane Katrina. Part IV: Orleans east bank (metro) protected basin." J. Geotech. Geoenviron. Eng., 134(5), 762-779.

Spencer, E. (1967). "A method of analysis of the stability of embankments assuming parallel interslice forces." Geotechnique, 17(1), $11-26$.

United States Army Corps of Engineers (USACE). (1990). "Orleans parish (Jefferson Parish) 17th Street Outfall Canal." Metairie Relief, Design Memorandum No. DM20 General Design, Vols. 1 and 2, Dept. of the Army, New Orleans District, Corps of Engineers, New Orleans.

URS Corporation and Arup Group (URS/ARUP). (2005) “Test fill construction, monitoring, and evaluation. Part II: Performance after construction.” Rep., Six Month Monitoring Program, Hamilton Wetlands Restoration Project, U.S. Army Corps of Engineers, San Francisco.

Van Heerden, I. L., et al. (2006). "The failure of the New Orleans levee system during hurricane Katrina." State Project No. 704-92-0022, 20. 〈http://www.publichealth.hurricane.lsu.edu/TeamLA.htm〉.

Wooley, D., and Shabman, L. (2007). "Decision making chronology for the Lake Pontchartrain and vicinity hurricane protection project." Draft Final Rep. U.S. Army Corps of Engineers, 〈http://www.iwr. usace.army.mil/inside/products/pub/hpdc/DraftFinalHPDC3.pdf $\rangle$ (June 2007).

Wright, S. G. (1999). UTEXAS4 - A computer program for slope stability calculations, Shinoak Software, Austin, Tex. 